OPEN ACCESS

Edited by:

Agustín Ruiz Laza,

Fundació ACE, Spain

Reviewed by:

Guohao Wang,

National Institutes of Health (NIH),

United States

Thomas Wisniewski,

New York University, United States

*Correspondence:

Ramesh Kandimalla

ramesh.kandimalla@gmail.com

Rajkumar Singh Kalra

rajkumar-singh@oist.jp

${ }^{\dagger}$ Present address:

Rajkumar Singh Kalra

Immune Signal Unit,

Okinawa Institute of Science and Technology Graduate University,

Okinawa, Japan

Received: 01 February 2021 Accepted: 05 May 2021 Published: 03 June 2021

Citation:

Kalra RS, Dhanjal JK, Meena AS,

Kalel VC, Dahiya S, Singh B,

Dewanjee $S$ and Kandimalla $R$

(2021) COVID-19, Neuropathology,

and Aging: SARS-CoV-2 Neurological Infection, Mechanism, and Associated Complications.

Front. Aging Neurosci. 13:662786. doi: 10.3389/fnagi.2021.662786

\title{
COVID-19, Neuropathology, and Aging: SARS-CoV-2 Neurological Infection, Mechanism, and Associated Complications
}

\begin{abstract}
Rajkumar Singh Kalra ${ }^{1 * t}$, Jaspreet Kaur Dhanjal ${ }^{2}$, Avtar Singh Meena ${ }^{3}$, Vishal C. Kalel ${ }^{4}$, Surya Dahiya ${ }^{5}$, Birbal Singh ${ }^{6}$, Saikat Dewanjee ${ }^{7}$ and Ramesh Kandimalla ${ }^{8,9 *}$

${ }^{1}$ AIST-INDIA DAILAB, National Institute of Advanced Industrial Science and Technology (AIST), Tsukuba, Japan, ${ }^{2}$ Department of Computational Biology, Indraprastha Institute of Information Technology Delhi, Okhla Industrial Estate, New Delhi, India, ${ }^{3}$ CSIR-Centre for Cellular and Molecular Biology (CCMB), Hyderabad, India, ${ }^{4}$ Department of Systems Biochemistry, Institute of Biochemistry and Pathobiochemistry, Faculty of Medicine, Ruhr-University Bochum, Bochum, Germany, ${ }^{5}$ Conservative Dentistry and Endodontics, Maharishi Markandeshwar College of Dental Sciences and Research, Ambala, India, ${ }^{\circ} / C A R$-Indian Veterinary Research Institute (IVRI), Regional Station, Palampur, India, '7Advanced Pharmacognosy Research Laboratory, Department of Pharmaceutical Technology, Jadavpur University, Kolkata, India, ${ }^{8}$ Applied Biology, CSIR-Indian Institute of Chemical Technology (IICT), Hyderabad, India, ${ }^{9}$ Department of Biochemistry, Kakatiya Medical College, Warangal, India
\end{abstract}

The spectrum of health complications instigated by coronavirus disease 2019 (COVID19 , caused by the novel severe acute respiratory syndrome coronavirus 2 or SARSCoV-2) pandemic has been diverse and complex. Besides the evident pulmonary and cardiovascular threats, accumulating clinical data points to several neurological complications, which are more common in elderly COVID-19 patients. Recent pieces of evidence have marked events of neuro infection and neuroinvasion, producing several neurological complications in COVID-19 patients; however, a systematic understanding of neuro-pathophysiology and manifested neurological complications, more specifically in elderly COVID-19 patients is largely elusive. Since the elderly population gradually develops neurological disorders with aging, COVID-19 inevitably poses a higher risk of neurological manifestations to the aged patients. In this report, we reviewed SARSCoV-2 infection and its role in neurological manifestations with an emphasis on the elderly population. We reviewed neuropathological events including neuroinfection, neuroinvasion, and their underlying mechanisms affecting neuromuscular, central- and peripheral- nervous systems. We further assessed the imminent neurological challenges in the COVID-19 exposed population, post-SARS-CoV-2-infection. Given the present state of clinical preparedness, the emerging role of $\mathrm{Al}$ and machine learning was also discussed concerning COVID-19 diagnostics and its management. Taken together, the present review summarizes neurological outcomes of SARS-CoV-2 infection and associated complications, specifically in elderly patients, and underlines the need for their clinical management in advance.

Keywords: COVID-19, SARS-CoV-2, neuropathology, aging, neuroinvasion, neuroinfection, pandemic, neurodegenerative disease 


\section{INTRODUCTION}

Primary physio-pathological evidence of Coronavirus Disease 2019 (COVID-19) exhibited severe respiratory and cardiovascular complications in the novel severe acute respiratory syndrome coronavirus 2 (SARS-CoV-2) infected patients. Emerging reports lately revealed that SARS-CoV2 infection develops a range of neurological complications (COVIDview, 2020). These complications are produced either by the direct contact of SARS-CoV-2 with the nervous system or by an indirect impact of immune-response during- or post-infection (Ellul et al., 2020). As an estimate, $\sim 35.6 \%$ of total COVID-19 cases were found to exhibit multiple neurologic manifestations (Tsai et al., 2020). Although neurological consequences of these events are evident across all age groups, yet, elderly COVID-19 patients remain at remarkably high risk (COVIDview, 2020). An acute phase of direct SARSCoV-2 infection could produce immediate neurological complications, however, a secondary phase might take months to surface after the infection (Beghi et al., 2020). Multiple nervous tissue/cell types including macrophages, microglia, or astrocytes are invaded by coronaviruses that can cause direct damage to the nerves (Beghi et al., 2020; Wu et al., 2020). Recent reports also underlined evidence of neurotoxicity primarily caused by immune injury, hypoxia-induced injury, and angiotensin-converting enzyme 2 (ACE2, a SARS-CoV2 host receptor) binding (Beghi et al., 2020; Wu et al., 2020). A recent systematic review analyzed the neuropathological features in patients who have died post-SARS-CoV-2 infection and it revealed that the majority of these patients were elderly $(n=66,45 \%)$ and males $(n=79,54 \%$; Pajo et al., 2021). The striking neuropathological features they exhibited include diffuse edema (17\%), gliosis (having diffuse microglia and astrocytes activation, 35.6\%), cortical and subcortical regional infarctions in the brain (2.7\%), intracranial (subarachnoid and punctate) hemorrhage (12.4\%), arteriosclerosis (29.5\%), hypoxic-ischemic injury (28.1\%), and inflammation (35.6\%). These observed features were suggested to be caused by direct cytopathic and indirect effects derived from host-specific inflammatory response post-SARS-CoV-2 infection (Pajo et al., 2021). These events greatly contribute to the development of neuro-pathophysiological symptoms in elderly COVID-19 patients. Although the long-term neurological complications in individuals who had COVID-19 are still unknown, similar viral infections were shown to exhibit neurological complications after months or years of infection by developing neuropsychiatric and cognitive impairment (Troyer et al., 2020).

The olfactory tract is a preferred route of coronavirus infection to the brain at an early stage, whereas evidence of brain invasion through systemic circulation is scarce (Wu et al., 2020). The common neurological complications resulting from direct infection are found to be encephalitis, myelitis, meningitis, and inflammatory central nervous system (CNS) vasculitis; whereas, immune-related CNS, peripheral nervous system (PNS) diseases, and the Guillain-Barré syndrome (GBS) emerged as the major post-infection complications (Beghi et al., 2020; Ellul et al., 2020). By an estimate, 20\% of the COVID-19 patients with ICU admittance had neurological complications and faced a high risk of mortality (Fotuhi et al., 2020). Of note, in elderly patients, SARS-CoV-2 instigated neurologic and immunologic complications that have produced severe consequences leading to neurodegenerative diseases (Lennon, 2020; Pavel et al., 2020). Taken together, in the present report we comprehensively reviewed the SARS-CoV-2 routes, neuro-infection or -invasion mechanism(s), their emergent and post-infection neurological manifestations, with a special focus on the elderly patients. We have also shed light on the emerging artificial intelligence (AI) and machine learning diagnostic applications for COVID-19 patients.

\section{SARS-COV-2 MANIFESTED NEUROLOGICAL COMPLICATIONS}

An early clinical case series from Wuhan, China revealed a significant relevance of SARS-CoV-2 infection with developing neurologic complications (Mao et al., 2020). It was estimated that out of 214 COVID-19 patients, 36.4\% developed neurologic complications including CNS manifestations (dizziness, headache, acute cerebrovascular disease, diminished consciousness, ataxia, and seizures), PNS manifestations (sensory ailments and neuralgia), and neuromuscular injury (Mao et al., 2020; Figure 1). A retrospective report from Wuhan showed that $5 \%$ of a total of 221 COVID-19 patients had incidences of acute ischemic stroke (Guan et al., 2020). A similar retrospective report from Wuhan revealed that 20\% of 113 COVID-19 patients suffered from hypoxic encephalopathy (Chen et al., 2020a).

To assess neurological complications in elderly COVID-19 patients, a cross-hospital nationwide investigation in the UK comprising 125 COVID-19 patients (avg. age 71 years) analyzed clinical data for neurological and psychiatric manifestations and revealed that $62 \%$ of the patients suffered from cerebrovascular events, among which $74 \%$ were reported with ischemic stroke, $23 \%$ developed unspecified encephalopathy and $1 \%$ acquired CNS vasculitis (Varatharaj et al., 2020). Noticeably, among the total patients, $31 \%$ developed altered mental complications-encephalitis (18\%) and intracerebral hemorrhage (12\%; Varatharaj et al., 2020). The remaining 59\% of the patients met the clinical case definitions of psychiatric diagnoses, among which $43 \%$ possessed new-onset psychosis, $26 \%$ acquired neurocognitive syndrome, and 17\% exhibited an affective disorder (Varatharaj et al., 2020). Of note, $82 \%$ of total enrolled COVID-19 patients having cerebrovascular events were aged more than 60 years, which is suggesting that elderly patients are at high risk for COVID-19 associated neurological complications advancing to greater lethality. A retrospective meta-analysis enrolling 1,558 COVID-19 patients from a total of six studies revealed that cerebrovascular disease is a potential risk factor (Wang et al., 2020a). A multi-centric report involving 184 COVID-19 patients admitted to ICU in three Dutch hospitals showed a considerably high $(31 \%)$ risk of thrombotic complications, while the death of 23 patients among these underlined the severity of such complications (Klok et al., 2020). A multi-centric retrospective study from Chicago, USA, further corroborated the fact that neurological 
manifestation is a major risk factor in hospitalized COVID-19 patients (Liotta et al., 2020). In this study, among the 509 COVID-19 patients, neurological manifestations were revealed at onset (42.2\%), hospitalization (62.7\%), and other stages of COVID-19 disease (82.3\%; Liotta et al., 2020). Another multicentric retrospective study of SARS-CoV-2 infected hospitalized patients in New York City assessed the prevalence of neurologic disorders, also it analyzed in-hospital mortality and compared manifested features between COVID-19 patients with and without neurologic disorders (Frontera et al., 2021). It strikingly revealed that $13.5 \%$ of patients developed a new neurologic disorder in 2 days median time from the onset of COVID-19 symptoms. It included toxic/metabolic encephalopathy (6.8\%), stroke $(1.9 \%)$, seizure (1.6\%), and hypoxic/ischemic injuries (1.4\%), though no patient had meningitis/encephalitis or myelopathy/myelitis due to SARS-CoV-2 infection (Frontera et al., 2021). Of note, neurologic disorders were more common in aged patients, wherein the male, white, diabetic, hypertensive, intubated population was vulnerable (all $p<0.05$ ) and faced an increased risk of in-hospital mortality and lesser recovery. This survey suggested that observed neurologic features may be sequelae of severe systemic illness (Frontera et al., 2021).

The neurologic manifestations i.e., myalgias, headaches, dizziness, dysgeusia, and anosmia, of all encephalopathies were found to be associated with poor health outcomes in admitted patients, irrespective of COVID-19 severity (Liotta et al., 2020; Figure 1). In the line, a 2-centric retrospective study from Spain also affirmed that neurological manifestations were frequent in admitted 841 COVID-19 patients (Romero-Sanchez et al., 2020). Montalvan et al. (2020) confirmed it further by systematically reviewing a total of 67 studies, wherein they found that risk of encephalitis, neuropathy, demyelination, and stroke are associated with COVID-19 (Montalvan et al., 2020). Providing insights on the SARS-CoV-2 infection route to the nerve tissue, it was revealed that the virus invasion occurs through the lamina cribrosa or olfactory tract and disperses through the transsynaptic transfer (Montalvan et al., 2020). Furthermore, another systematic review assessed a greater risk of secondary neurologic complications in hospitalized COVID-19 patients (Herman et al., 2020); while, another estimate claimed that 1 out of 3 COVID-19 patients could acquire an altered mental state (Belluck, 2020).

SARS-CoV-2 manifested complications that include the CNS, PNS, and neuromuscular system, range from mild to severe, and can also appear in patients with asymptomatic SARS-CoV2 infection. SARS-CoV-2 infects the host by establishing the binding of its spike (S) glycoproteins to the host ACE2 receptor that expresses in the brain, gastrointestinal tract (GI), respiratory tract, lung parenchyma, and endothelial cells, and therefore it serves as a potential target for the direct COVID-19 inhibitory regimens (Kalra et al., 2021) or indirect suppressive strategies including miRNAs (Li et al., 2018). The most common symptoms associated with SARS-CoV-2 are dry cough, fever, and lethargy; however, aged adults are more susceptible to severe infection involving shortness of breath, pneumonia, and acute respiratory distress syndrome (ARDS) leading to higher mortality incidence (Table 1). A natural decline in
ACE2 levels, elevated angiotensin signaling, and subsequently chronic low-grade inflammation that develops with advanced age, termed inflammaging, might contribute to the severity and comorbid diabetic and cardiovascular complications in aged individuals (Alghatrif et al., 2020; Kalra et al., 2020). SARS-CoV2 is a neuro-invasive and neurotrophic virus. Studies implicated that neurological manifestations are primarily associated with the severity of SARS-CoV-2 infection, which involves loss of taste, smell, consciousness, vision, seizures, neuralgia, and lack of coordination (Mao et al., 2020). SARS-CoV-2 can enter the CNS through the olfactory lobe and hematogenous route (Figure 2). A gradual decline of the blood-brain barrier (BBB) is associated with normal aging, which may enhance the effect of SARS-CoV-2 in aged individuals (Montagne et al., 2015). SARS$\mathrm{CoV}-2$ causes neurodegeneration, demyelination, and cellular senescence upon entry; all of these potentiate brain aging and aggravate the underlying pathophysiology of neurodegeneration (Lennon, 2020; Montalvan et al., 2020; Palao et al., 2020; Pavel et al., 2020).

At the beginning stage of infection, patients with the COVID-19 focus on managing cough, dyspnea, fever, and breathing complications. However, it is evident from studies that it gradually led to an increase in neurological complications, such as stroke, seizures, anosmia, encephalopathy, and paralysis ( $\mathrm{Li}$ et al., 2020b; Mao et al., 2020). In 2002 and 2013, during the epidemics of SARS-CoV-1 and Middle East Respiratory Virus (MERS) respectively, the virus caused a detrimental effect in multiple organs, including the brains, nerves, and neuromuscular tissues. SARS-CoV-2, shares homology with SARS-CoV-1 and MERS and therefore emerges as an essential player in causing CNS and PNS injury, either direct or indirect (Nath, 2020; Wu et al., 2020). Neurological abnormalities have been documented in the patients who required hospitalization for COVID-19, respiratory illness, and acute respiratory distress syndrome (ARDS; Helms et al., 2020; Mao et al., 2020). In a clinical case series, neurological symptoms are restricted to general conditions such as headache, loss of smell and taste, dizziness, and malaise in mild conditions, which are routinely observed with viral infection (Mao et al., 2020). Among 1,420 mild-tomoderately infected COVID-19 patients, $70 \%$ of the patients experienced headache, which is a prominent neurological manifestation. Noticeably, severe neurological complications can be seen in mild-infected COVID-19 patients in the multiple clinical reports, while patients with pre-existing comorbidities had severe complications resulting in significantly high mortality (Iadecola et al., 2020; Merkler et al., 2020; Oxley et al., 2020; Yaghi et al., 2020; Table 1).

\section{Central Nervous System (CNS) Manifestations}

Symptoms related to mental status such as confusion, tiredness, and agitation, collectively known as encephalopathy, have been described in the COVID-19 in few clinical reports (Table 1). Diagnostic criteria for detecting encephalitis have been established and include fever, seizures, focal brain abnormalities, disturbed mental status, and white blood cells in the lymphaticcerebrospinal fluid (CSF; Venkatesan et al., 2013). In the clinical 


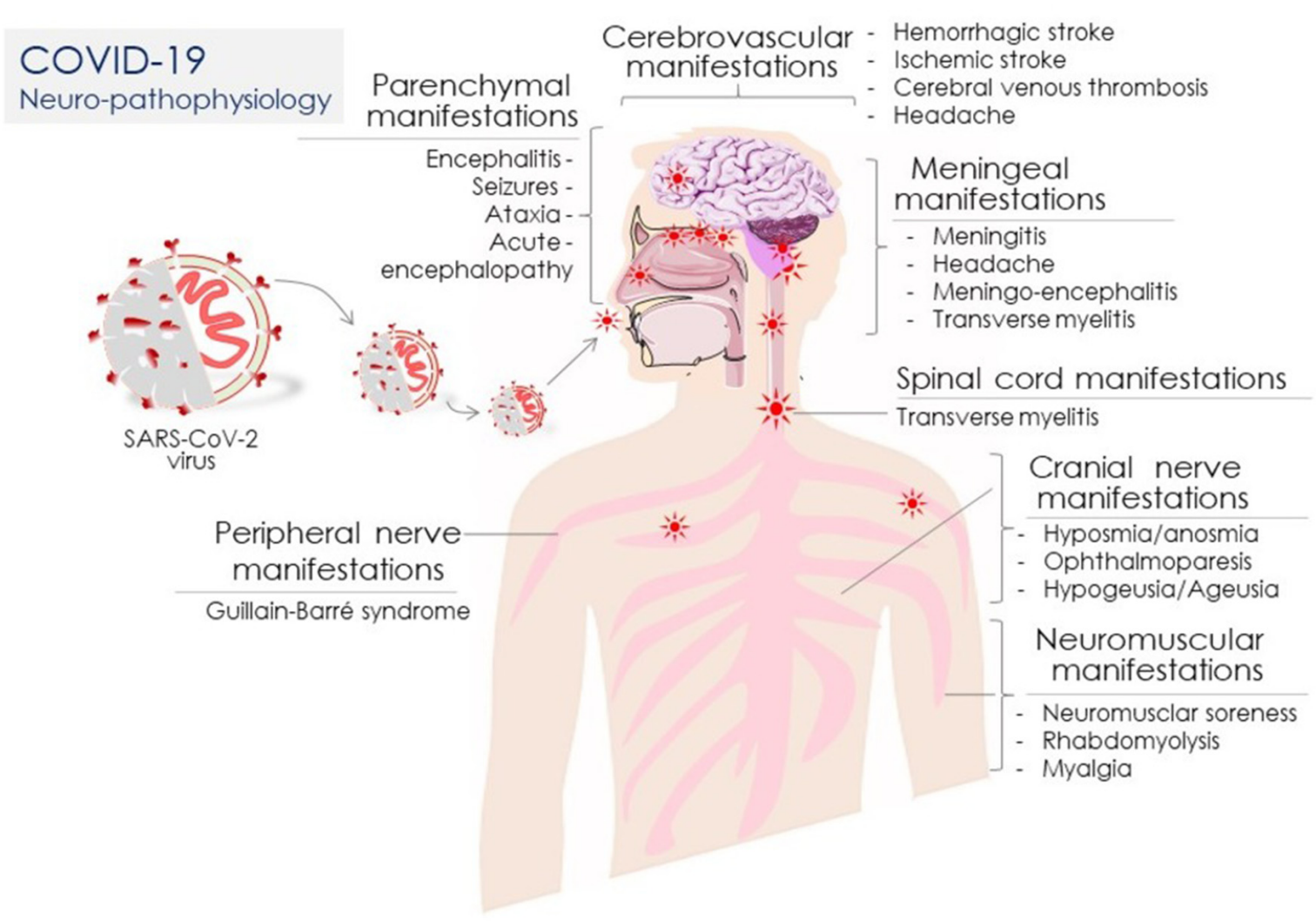

FIGURE 1 | Coronavirus disease 2019 (COVID-19) neuro-pathophysiology: COVID-19 clinical manifestations associated with diverse neuronal systems/organs including the peripheral nerve, parenchymal, cerebrovascular, meningeal, spinal cord, neuromuscular, and cranial nerve in SARS-CoV-2-infected patients.

case series, the cognitive level was primarily affected in most critically ill COVID-19 patients with ARDS (Helms et al., 2020) compared to COVID-19 patients with only respiratory illness (Mao et al., 2020). It is unclear whether the alteration in mental status is due to encephalitis caused by systemic disease or directly caused by SARS-CoV-2 infection. However, several reports suggest that COVID-19 patients exhibited well-established diagnostic markers for encephalitis (Efe et al., 2020; Farhadian et al., 2020; Huang et al., 2020a; Pilotto et al., 2021). In the very first reported case of meningitis/encephalitis associated with COVID-19, Moriguchi et al. (2020) observed SARS-CoV-2 level in the CSF but found only a modest amount of viral RNA load. In another case study, a biopsy from COVID-19 patient showed neuronal loss due to hypoxia and perivascular lymphocyte infiltration confirming temporal lobe encephalitis (Efe et al., 2020). However, Efe et al. (2020) did not detect SARS-CoV-2 in the brain or CSF. Brain tissue samples from autopsies of COVID-19 patients negative for evidence of encephalitis and CSF samples from COVID-19 patients with neurological abnormalities have not revealed evidence of SARS-CoV-2 (Kandemirli et al., 2020). Other significant mental status indicators such as confusion, delirium, and coma may be common symptoms in COVID-19 patients. These indicators are frequently associated with hypotension, kidney disease, usage of sedatives, hypoxia, and prolonged bedridden and isolation conditions-all these factors are significant contributors to the progression of encephalopathy (Helms et al., 2020; Mao et al., 2020; Martin-Jimenez et al., 2020; Maas et al., 2021; Rogers et al., 2021). Although SARS-CoV-2 affects all ages, adults aged 65 and older are at higher risk of severe disease, hospitalization, ICU use, and death. Geriatric age patients are prone to loss of consciousness, disorientation, and other cognitive disturbances. Delirium is a common symptom of older people with COVID-19 during hospitalization. Despite the lack of clinical data and histopathological evidence of encephalitis and occurrence of other alternative events impacting mental status, these data so far hint that the potential invasion of SARS-CoV-2 in the brain may be the sporadic cause of encephalopathy.

In retrospective clinical studies, 11 patients out of 221 showed acute ischemic stroke, along with one patient who developed cerebral venous thrombosis and cerebral hemorrhage. The majority of these patients were elderly and were suffering from severe COVID-19 along with common comorbidities (Li et al., 2020b). A small clinical case study from the UK, comprising six severely affected patients showed cerebral infarcts and elevated D-dimer levels, suggesting a coagulopathy (Beyrouti et al., 2020). In another small case study of five young patients, COVID-19 


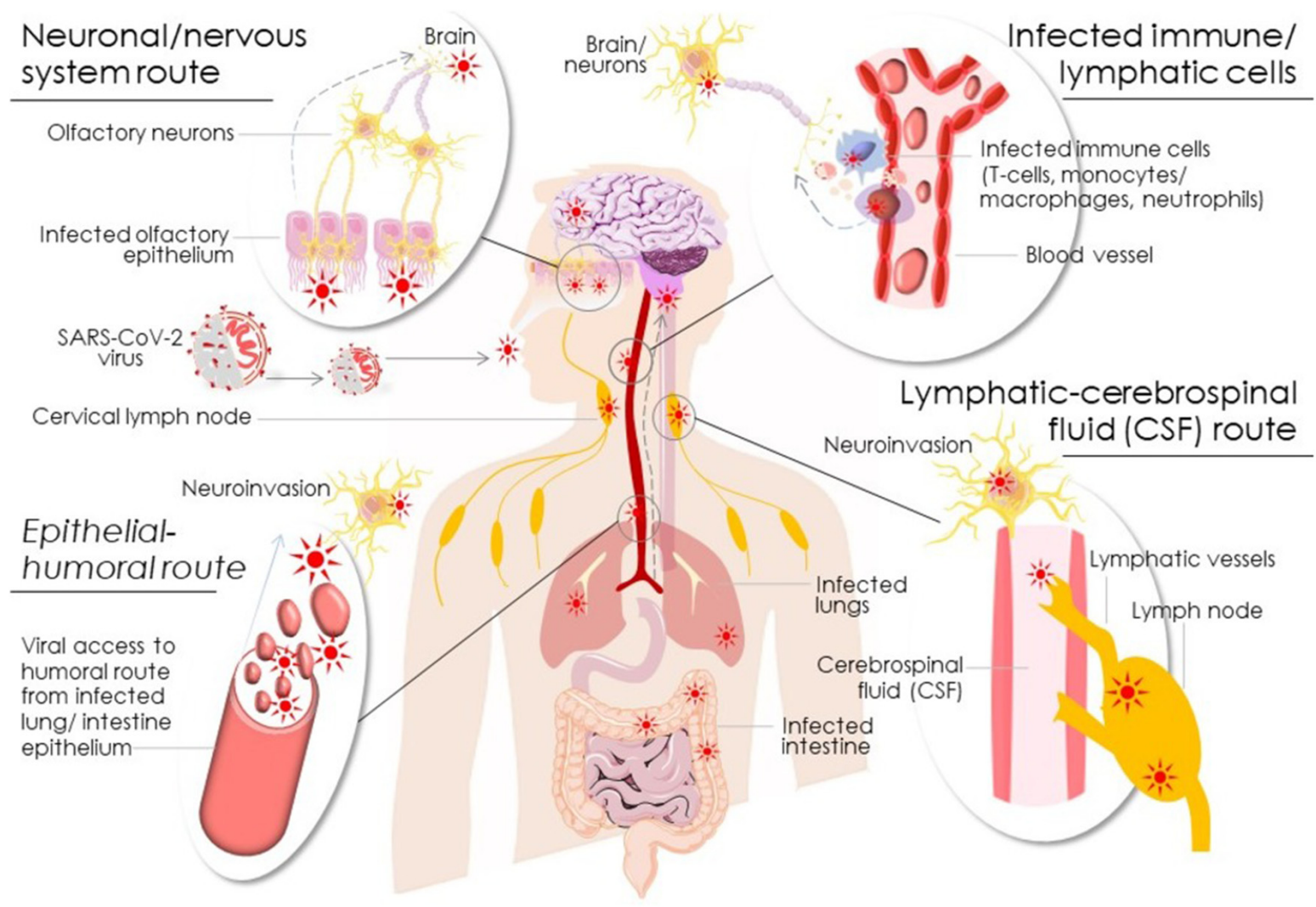

FIGURE 2 | Schematic diagram showing potential modes of SARS-CoV-2 neuroinfection via neuronal/nervous, epithelial-humoral, infected immune/lymphatic, and lymphatic-cerebrospinal fluid routes.

related strokes were shown to cause large-vessel infarct (Oxley et al., 2020). Al Saiegh et al. (2020) in a small case report, could not demonstrate the presence of SARS-CoV-2 in the CSF of aged patients that had an ischaemic stroke. Hypoxia, produced by lack of oxygen, increases stroke incidence due to impairment in sleep structure, increases blood pressure, atherosclerosis, promotes micro thrombosis, and decreases the blood flow (Lee et al., 2019). In a case series, Mao et al. (2020) showed that six hospitalized COVID-19 patients exhibited acute cerebrovascular disease, among these, five had a severe infection (5/88) and one was in non-severe condition (1/125). The symptoms of hypoxia are coupled with COVID-19, and it was predicted to be a consequence of S-protein's interaction with hemoglobin (Agrawal et al., 2021); therefore, it was believed to potentiate the patient's necessity for ventilator support. Of note, in a single-centric case series, the COVID-19 patients admitted to ICU were relatively old, and they had a more significant number of comorbid conditions, such as diabetes, cardiovascular complication, hypertension, and cerebrovascular disease, in comparison to those who did not require ICU (Wang et al., 2020b). The findings of this clinical case series imply that aging and comorbidities may be risk factors for poor neurological and survival outcomes (Wang et al., 2020a; Table 1). Seizure is a rare symptom in the COVID-19 setting.
Reports involving a retrospective multi-centric study and a case series could not observe stroke in COVID-19 patients despite metabolic alteration ( $\mathrm{Lu}$ et al., 2020; Mao et al., 2020).

\section{Peripheral Nervous System (PNS) Manifestations}

Moein et al. (2020) in the earliest analysis derived from a cohort of 100 COVID-19 patients showed that loss of smell sensation (anosmia) and taste sensation (ageusia) is the most common neurological manifestation of COVID-19, even in mild to moderate cases. Smell sensation is more affected compared to the taste sensation. Emerging evidence suggests that SARS-CoV-2 can enter the neuronal cells through the olfactory nerve and spreads to the olfactory bulb (Figure 2). Lechien and colleagues in a multi-centric European study and a case report showed that $86 \%$ and $88 \%$ of COVID- 19 patients respectively, reported the loss of smell and taste (Lechien et al., 2020a,b). Cranial neuropathy is an erratic event in the setting of COVID-19; however, one case study involving a 40-year-old female COVID-19 patient showed isolated oculomotor nerve palsy in severely ill patients, which could be due to inflammatory reaction against SARS-CoV-2 (Wei et al., 2020). COVID-19 can cause detrimental effects 
TABLE 1 | Summary of common peripheral nervous system (PNS), central nervous system (CNS), cerebrovascular, and intracerebral neurological complications in elderly Coronavirus disease 2019 (COVID-19) patients.

\begin{tabular}{|c|c|c|c|c|c|}
\hline $\begin{array}{l}\text { Neurological } \\
\text { complications }\end{array}$ & Manifestations & $\begin{array}{l}\text { Investigation/Region/ } \\
\text { Study type }\end{array}$ & Clinical features/Symptoms & $\begin{array}{l}\text { COVID-19 } \\
\text { Diagnostics }\end{array}$ & $\begin{array}{l}\text { Neurological investigation } \\
\text { (CSF scans, neuroimaging, } \\
\text { neurophysiology) }\end{array}$ \\
\hline \multirow[t]{5}{*}{ CNS disease } & \multirow[t]{3}{*}{ Encephalitis } & $\begin{array}{l}\text { Sohal and Mansur (2020); } \\
1 \text { case, USA, Case report. }\end{array}$ & $\begin{array}{l}\text { 72-year-old male patient. Weakness and } \\
\text { lightheadedness. Altered mental status; } \\
\text { Seizures (On day } 2 \text { post-hospitalization). }\end{array}$ & RT-PCR + ve & $\begin{array}{l}\text { Head CT: no acute changes. 24-h } \\
\text { EEG: six left temporal seizures and } \\
\text { left temporal sharp waves that were } \\
\text { epileptogenic. }\end{array}$ \\
\hline & & $\begin{array}{l}\text { Paniz-Mondolfi et al. (2020); } \\
1 \text { case, USA, Case report. }\end{array}$ & $\begin{array}{l}\text { 74-year-old male patient. History of } \\
\text { Parkinson's disease. Fever, confusion, and } \\
\text { agitation. }\end{array}$ & $\begin{array}{l}\text { RT-PCR + ve } \\
\text { (nasopharyngeal) }\end{array}$ & Head CT: no acute changes. \\
\hline & & $\begin{array}{l}\text { Zhou et al. (2020b); } 1 \text { case, } \\
\text { China, Case report. }\end{array}$ & $\begin{array}{l}\text { 56-year-old patient. SARS-CoV-2 infection } \\
\text { and pneumonia. }\end{array}$ & $\begin{array}{l}\text { SARS-CoV2 + ve (CSF } \\
\text { sequencing) }\end{array}$ & $N R$ \\
\hline & $\begin{array}{l}\text { Acute disseminated } \\
\text { encephalomyelitis }\end{array}$ & $\begin{array}{l}\text { Zanin et al. (2020); } 1 \text { case, } \\
\text { Italy, Case report. }\end{array}$ & $\begin{array}{l}\text { 54-year-old female patient. Agitation, } \\
\text { decreased consciousness, and seizures } \\
\text { after many days of ageusia and anosmia. }\end{array}$ & RT-PCR + ve & $\begin{array}{l}\text { CSF: normal; Brain and spine MRI: } \\
\text { periventricular confluent white } \\
\text { matter lesions. Numerous cord } \\
\text { lesions from (bulbomedullary } \\
\text { junction to T6 level). }\end{array}$ \\
\hline & Myelitis & $\begin{array}{l}\text { Zhao et al. (2020b); } 1 \text { case, } \\
\text { China, Case report. }\end{array}$ & $\begin{array}{l}\text { 66-year-old male patient. Fever, dyspnoea, } \\
\text { and asthma. Developed acute flaccid } \\
\text { paralysis of lower limbs ( } 5 \text { days after the } \\
\text { beginning of respiratory symptom). Urinary } \\
\text { and fecal incontinence. Sensory level at } \\
\text { T10. }\end{array}$ & $\begin{array}{l}\text { RT-PCR + ve } \\
\text { (nasopharyngeal) }\end{array}$ & $\begin{array}{l}\text { Brain CT: lacunar infarcts; spinal } \\
\text { imaging not done }\end{array}$ \\
\hline \multirow[t]{2}{*}{ PNS disease } & \multirow[t]{2}{*}{$\begin{array}{l}\text { Guillain-Barré } \\
\text { syndrome }\end{array}$} & $\begin{array}{l}\text { Camdessanche et al. } \\
\text { (2020); } 1 \text { case, France, } \\
\text { Case report. }\end{array}$ & $\begin{array}{l}\text { 64-year-old male patient. Developed } \\
\text { paraesthesia and progressive weakness in } \\
\text { all limbs. Areflexia and loss of vibration } \\
\text { sense. Later developed dysphagia and } \\
\text { respiratory insufficiency. }\end{array}$ & $\begin{array}{l}\text { RT-PCR + ve } \\
\text { (nasopharyngeal) }\end{array}$ & $\begin{array}{l}\text { CSF: normal. Nerve conduction and } \\
\text { electromyography: acute } \\
\text { inflammatory demyelinating } \\
\text { polyneuropathy. }\end{array}$ \\
\hline & & $\begin{array}{l}\text { Zhao et al. (2020b); } 1 \text { case, } \\
\text { China, Case report. }\end{array}$ & $\begin{array}{l}\text { 61-year-old female patient. Progressive } \\
\text { weakness of limbs and severe fatigue. } \\
\text { Areflexia in lower limbs and reduced } \\
\text { sensation distally. Dry cough and fever (after } \\
7 \text { days). }\end{array}$ & $\begin{array}{l}\text { RT-PCR + ve } \\
\text { (oropharyngeal) }\end{array}$ & $\begin{array}{l}\text { CSF: normal. Nerve conduction } \\
\text { study: acute inflammatory } \\
\text { demyelinating polyneuropathy. }\end{array}$ \\
\hline \multirow[t]{2}{*}{$\begin{array}{l}\text { GBS variants and } \\
\text { other neuropathies }\end{array}$} & $\begin{array}{l}\text { Miller-Fisher } \\
\text { Syndrome }\end{array}$ & $\begin{array}{l}\text { Gutierrez-Ortiz et al. (2020); } \\
1 \text { case, Spain, Case report. }\end{array}$ & $\begin{array}{l}\text { 64-year-old male patient. Cough, fever, } \\
\text { malaise, anosmia, headache, and ageusia. } \\
\text { Developed right inter-nuclear } \\
\text { opthalmoparesis with right fascicular } \\
\text { oculomotor palsy, ataxia, and areflexia. }\end{array}$ & RT-PCR + ve(oropharyngeal) & $\begin{array}{l}\text { CSF: normal. Brain CT with } \\
\text { contrast: normal. }\end{array}$ \\
\hline & Ophthalmoplegia & $\begin{array}{l}\text { Dinkin et al. (2020); } 1 \text { in } \\
\text { USA, Case report. }\end{array}$ & $\begin{array}{l}\text { 71-year-old female patient. Had isolated } \\
\text { ophthalmoplegia (post-few days of cough } \\
\text { and fever; right abducens palsy). }\end{array}$ & RT-PCR + ve (nasal) & $\begin{array}{l}\text { CSF: normal opening pressure; } \\
\text { brain MRI: enhancement of the } \\
\text { optic nerve sheaths and posterior } \\
\text { Tenon capsules. }\end{array}$ \\
\hline
\end{tabular}


TABLE 1 | Continued

\begin{tabular}{|c|c|c|c|c|c|}
\hline $\begin{array}{l}\text { Neurological } \\
\text { complications }\end{array}$ & Manifestations & $\begin{array}{l}\text { Investigation/Region/ } \\
\text { Study type }\end{array}$ & Clinical features/Symptoms & $\begin{array}{l}\text { COVID-19 } \\
\text { Diagnostics }\end{array}$ & $\begin{array}{l}\text { Neurological investigation } \\
\text { (CSF scans, neuroimaging, } \\
\text { neurophysiology) }\end{array}$ \\
\hline & Rhabdomyolysis & $\begin{array}{l}\text { Jin and Tong (2020); } 1 \text { case } \\
\text { of rhabdomyolysis, China, } \\
\text { Case report. }\end{array}$ & $\begin{array}{l}\text { 60-year-old male patient. Weakness and } \\
\text { tenderness in lower limbs ( } 15 \text { days after } \\
\text { beginning of fever and cough). }\end{array}$ & RT-PCR + ve (throat swab) & $N R$ \\
\hline \multirow[t]{5}{*}{$\begin{array}{l}\text { Cerebrovascular } \\
\text { disease }\end{array}$} & Ischaemic stroke & $\begin{array}{l}\text { Avula et al. (2020); 4cases, } \\
\text { USA, Case series. }\end{array}$ & $\begin{array}{l}4 \text { patients ( } 73-88 \text { years old). Had } \\
\text { hypertension; } 3 \text { had dyslipidaemia, } \\
1 \text { diabetes and neuropathy. } 3 \text { patients } \\
\text { exhibited acute new focal neurological } \\
\text { deficit and } 1 \text { showed altered mental status. }\end{array}$ & All RT-PCR + ve & $\begin{array}{l}\text { All } 4 \text { had unifocal infarcts: } 3 \text { on CT, } \\
1 \text { on brain MRI. }\end{array}$ \\
\hline & & $\begin{array}{l}\text { Beyrouti et al. (2020); } \\
6 \text { cases, UK, Case report. }\end{array}$ & $\begin{array}{l}6 \text { patients ( } 53-83 \text { years old. } 5 \text { male and } \\
1 \text { female). } 3 \text { had hypertension, } 2 \text { ischemic } \\
\text { heart disease, } 2 \text { atrial fibrillations, } 1 \text { had } \\
\text { previous stroke, and } 1 \text { was a heavy smoker } \\
\text { and alcohol drinker. All had respiratory } \\
\text { symptoms (at avg. } 13 \text { days) before or after } \\
\text { neurological symptom onset. }\end{array}$ & All RT-PCR + ve & $\begin{array}{l}\text { Scans (CT and brain MRI) showed } \\
\text { unifocal infarcts in } 4 \text { patients. } 1 \text { had } \\
\text { bilateral infarcts on a follow-up brain } \\
\text { MRl; } 2 \text { had bilateral infarcts on initial } \\
\text { scans. }\end{array}$ \\
\hline & & $\begin{array}{l}\text { Li et al. (2020a); } 11 \text { cases, } \\
\text { China, Single-center, } \\
\text { retrospective study. }\end{array}$ & $\begin{array}{l}11 \text { patients ( } 57-91 \text { years old; } 6 \text { female and } \\
5 \text { male). } 9 \text { had hypertension, } 6 \text { diabetes, } \\
3 \text { cardiovascular disease. All had respiratory } \\
\text { symptoms (at avg. } 11 \text { days) before } \\
\text { neurological symptoms onset. }\end{array}$ & All RT-PCR + ve & NR \\
\hline & & $\begin{array}{l}\text { Morassi et al. (2020); } \\
4 \text { cases, Italy, Case series. }\end{array}$ & $\begin{array}{l}4 \text { patients (64-82 years old). } 3 \text { had } \\
\text { hypertension, } 2 \text { had a previous stroke or } \\
\text { transient ischemic condition and aortic } \\
\text { valve disease, and } 1 \text { was a smoker with a } \\
\text { previous myocardial infarction. } 3 \text { developed } \\
\text { neurological manifestations during } \\
\text { hospitalization, } 1 \text { exhibited episodes of } \\
\text { transient loss of consciousness. }\end{array}$ & $\begin{array}{l}\text { All RT-PCR + ve } \\
\text { (nasopharyngeal) }\end{array}$ & $\begin{array}{l}1 \text { patient had CSF: normal } \\
\text { leukocyte count, protein, and IgG } \\
\text { index. All had multifocal infarcts on } \\
\text { brain CT or MRI; the patient } \\
\text { presenting with transient loss of } \\
\text { consciousness and ensuing } \\
\text { confusion. }\end{array}$ \\
\hline & $\begin{array}{l}\text { Intracerebral } \\
\text { hemorrhage }\end{array}$ & $\begin{array}{l}\text { Morassi et al. (2020); } \\
2 \text { cases, Italy, Case series. }\end{array}$ & $\begin{array}{l}2 \text { patients ( } 57 \text { years old). Admitted to } \\
\text { hospital with critical COVID- } 19 \text { condition; (at } \\
14 \text { and } 17 \text { days after onset of cough and } \\
\text { fever), they had bilaterally fixed dilated } \\
\text { pupils and coma (GCS } 3 / 15 \text { ). }\end{array}$ & $\begin{array}{l}\text { Both RT-PCR + ve } \\
\text { (nasopharyngeal) }\end{array}$ & $\begin{array}{l}1 \text { patient had bilateral cerebellar } \\
\text { hemorrhages on brain CT with } \\
\text { hydrocephalus; the other had a } \\
\text { large frontal hemorrhage with } \\
\text { displaced ventricles and multiple } \\
\text { smaller hemorrhages. }\end{array}$ \\
\hline
\end{tabular}


to the peripheral nerves, cranial nerve, and neuromuscular tissue. Dyspnea, facial weakness, inability to stand or walk, or struggling with weaning off respiratory ventilators might be partially due to GBS expedited by COVID-19. GBS is frequently observed neurological complications in COVID-19 (Zhao et al., 2020a). Miller-Fisher syndrome is measured by the acute onset of external loss of tendon reflexes, ataxia, and ophthalmoplegia. In a clinical case report in Spain, involving a hospitalized 64-year old male COVID-19 patient, clinical features and eye movement abnormalities were found to be consistent with the diagnosis of Miller-Fisher Syndrome and polyneuritis cranialis. The symptoms consisted of ataxia, fascicular palsy, areflexia, anosmia, and ageusia (Table 1). This patient received Intravenous immunoglobulin (IVIg) and showed rapid recovery (Gutierrez-Ortiz et al., 2020). In a case report from three hospitals in northern Italy, comprising five patients who had GBS syndrome, one patient diagnosed with COVID-19 exhibited sensory ataxia, facial weakness, and facial nerve, though this patient responded positively to the treatment with IVIg and improved within a week (Toscano et al., 2020). The other four patients showed more GBS and a variable degree of COVID-19 symptoms. The severity and mortality of COVID-19 patients depend on age and pre-existing comorbidities, and ongoing treatment regimen. Multiple sclerosis (MS) is particularly prevalent in young adults; however, a substantial number of individuals with MS are older than 60 years (Minden et al., 2004). Managing MS during the COVID-19 pandemic is critical for patient's health management as there are no evidence-based guidelines and published literature yet available. In general, elderly patients ( $\geq 65$ years) are susceptible to COVID-19 severity and mortality. Analyses from a Sonya Slifka Longitudinal MS study indicated that $10-20 \%$ of MS patients are more than 65 years old (Minden et al., 2004). However, whether it could impact the COVID-19 mortality in older patients given their impaired immune regulation, yet need to be elucidated (Berger et al., 2020). Besides the age, other comorbidities are correlated in the MS population cohorts as well with increased risk of severity and mortality (reviewed by Marrie et al., 2015a,b).

In one cross-sectional study in Europe, 1,931 MS patients were engaged to determine the mortality associated with COVID-19 (Bsteh et al., 2020). Out of 1,931 patients, 63\% showed a low risk of COVID-19 mortality, 26\% had mild risk, $8.8 \%$ had moderate risk, while $0.9 \%$ exhibited a high risk of COVID-19 mortality. Only one patient received diseasemodifying treatment (DMT) in the high-risk category, and none had any immunosuppressive therapy. The increased risk of COVID-19 mortality is below $1 \%$ in the population-based MS cohort (Bsteh et al., 2020). At the beginning of the COVID-19 pandemic, clinicians recommended delaying treatment with DMT in MS patients (Giovannoni et al., 2020). Recent data has suggested that COVID-19 positive MS patients are not different from the general MS population (Parrotta et al., 2020). However, clinicians and physicians need to be vigilant for prescribing the drugs and recommendations regarding MS to guide their patients during the COVID-19 pandemic.

\section{Neuromuscular Dysfunction/Injury}

As per a clinical case series analysis of 214 COVID-19 patients, $11 \%$ of patients were reported to have evidence of neuromuscular injury (Mao et al., 2020). The damage was more prominent in severely affected (19\%) than non-severely affected individuals (5\%); however, these results do not indicate whether the damage is due to the COVID-19 neuromuscular infection. Such injuries were suggested to be due to SARS-CoV2 infection-mediated release of pro-inflammatory cytokines. However, no clinical details are yet available beyond the presence of neuromuscular pain. Lately, two reports suggested it to be rhabdomyolysis as its clinical features were manifested in COVID-19 infected patients (Jin and Tong, 2020; Suwanwongse and Shabarek, 2020). Rhabdomyolysis is skeletal/neuromuscular damage that can be a manifestation of COVID-19. In a case report, a 35-year-old female was found to have rhabdomyolysis correlated with COVID-19 (Alrubaye and Choudhury, 2020). Clinical data from the report suggests that clinicians should examine the level of liver enzyme and myalgia, which could serve as clinical features of rhabdomyolysis in COVID-19 patients. Detailed analysis of the CSF pro-inflammatory and T-cell response to SARS-CoV-2 is urgently warranted to comprehensively understand the neuromuscular manifestation in COVID-19 patients.

Although we presently lack a distinct and detailed analysis of SARS-CoV-2 -manifested neurological complications including CNS, PNS, and neuromuscular injuries in the aged population, we summarize the key clinical reports/case studies involving elderly COVID-19 patients in Table $\mathbf{1}$.

\section{POST COVID-19-INFECTION NEUROLOGICAL COMPLICATIONS: WHAT IS KNOWN SO FAR}

Like COVID-19, other coronaviruses viz. SARS-CoV-1 and Middle East respiratory syndrome (MERS-CoV) have also been associated with various prolonged neurological complications (Chan et al., 2003; Lee et al., 2018). As discussed earlier, the most common neurological difficulties in COVID-19 include anosmia, ageusia, and headache, moreover, more serious complications, such as stroke, impaired consciousness, seizures, and encephalopathy have also been reported. Reports on these neurological and neuropsychological complications during and after the course of COVID-19 infection are growing rapidly. Focusing on the aging population, we have here limited our discussion about post-COVID-19 neurological and neuropsychological complications reported only in elderly patients.

Acute disseminated encephalomyelitis (ADEM), an autoimmune disease of the CNS, that mainly affects children has been observed in SARS-CoV-2 infected patients. However, most of the cases reported to be diagnosed with ADEM post-COVID-19 have been aged 50 years or above. But this might be biased given the higher prevalence of COVID-19 in adults. Amongst these reported cases was a 51-year-old female who developed clinical coma and an impaired oculocephalic 
response to one side post-COVID-19 infection, which was later diagnosed to be acute multifocal demyelinating lesions (Parsons et al., 2020). Another case study reported a 64-yearold woman with ADEM, who was hospitalized with mild behavioral abnormalities, headache, bilateral relative afferent pupillary defect, ageusia and anosmia, severe visual loss, right abdominal sensory level, and left-sided lower limb hyperreflexia with the Babinski sign (Novi et al., 2020). Both these patients recovered with the administration of high-dose steroids and intravenous immunoglobulins. ADEM was also diagnosed in the post-mortem biopsy of a 71-year-old male (Reichard et al., 2020). In another case study, similar immune-mediated brain damage was also detected in a 58-year-old male patient. The patient was hospitalized with low consciousness and loss of ability to walk. The patient was tested positive for SARS$\mathrm{CoV}-2$ infection even though pulmonary symptoms like cough or dyspnea were not observed. Though the patient initially responded to steroids but then died of status epilepticus (Abdi et al., 2020). Another case study of a likewise neurological syndrome that commonly called as acute myelitis has also been reported in a 69-year-old female (Sotoca and Rodriguez-Alvarez, 2020). The first clinical case of COVID-19 associated acute necrotizing hemorrhagic encephalopathy was reported by Poyiadji et al. (2020) in a 58-year-old female airline worker. This rare neurological condition was attributed to intracranial cytokine storm and disruption of the BBB without the direct viral invasion (Serrano-Castro et al., 2020). Investigating the case study of a 75-year-old man, Hayashi et al. (2020) have suggested that mild encephalitis/encephalopathy with reversible splenial lesion can also be considered as a neurological symptom in patients developing transient cerebellar ataxia or disorientations. To add to this list of neurological complications, vasculitis of CNS has also been reported to occur in a 65-year-old man (Hanafi et al., 2020). Along with CNS, the PNS has also been affected in COVID-19 patients. Pascual-Goni et al. (2020) reported a 60-year-old female patient who after 10 days of fever, hyposmia, nausea, and coughing experienced diplopia and right hemicranial headache that was later diagnosed as right abducens nerve palsy.

In terms of post-COVID-19 neuropsychological impact, a study concerning 700 clinically stable COVID-19 patients (mean age $50.2 \pm 12.9$ years) were examined for post-traumatic stress symptoms, and nearly $96 \%$ of the patient were found to be suffering from significant post-traumatic stress (Bo et al., 2020). A much larger cohort study involving 112 hospitalized patients and 2,001 non-hospitalized patients from Belgium and Netherland has revealed that symptoms like neuromuscular pain, dizziness, headaches, fatigue, and anosmia prevail also in asymptomatic or very mildly symptomatic patients even after months of contracting the disease (Goertz et al., 2020). Some patients treated for severe COVID-19 have been reported with disabling fatigue and impaired cognitive abilities after being discharged from the hospitals (Zhou et al., 2020a; Halpin et al., 2021). Also, the detection of delirium, the most common acute neuropsychiatric syndrome, has been significantly linked to COVID-19 in older adults and those with dementia (Poloni et al., 2020).

\section{UNDERSTANDING THE SARS-COV-2 INFECTION AND ITS ROUTES}

Considering these features of neuropathological manifestations discussed above, here we shed light on the SARS-CoV2 infection, its diverse routes, the mechanism(s), and associated neurological complications.

\section{POTENTIAL SARS-COV-2 INFECTION ROUTES}

The neurotropic, neuroinvasive, and neurovirulent characteristics of SARS-CoV-2 were recognized in both humans and animals (Lima et al., 2020). Recent evidence suggested that coronaviruses can infect primary human neural cells, microglia, astrocytes, and oligodendrocytes (Lima et al., 2020). SARS-CoV-2 interacts with the host ACE2 receptor through the receptor-binding domain (RBD) of its Spike (S) protein. ACE2 receptor ubiquitously expresses in all human tissues including CNS and the endothelial cells. Emerging evidence reveals that SARS-CoV-2 binds to the ACE2 receptor to invade neurons in CNS via distinct routes as discussed here (Figure 2).

\section{Epithelial-Humoral Route}

Coronaviruses can efficiently invade the epithelial-humoral route and disrupt the primary epithelial barrier to attain access into the bloodstream. ACE2 abundantly expresses on the alveolar epithelial cells (Type II) that makes these cells a preferred target for SARS-CoV-2 infection (Lima et al., 2020). Also, an abundant expression of ACE2 on the epithelial cells of the gastrointestinal tract raises their vulnerability for SARS-CoV2 infection and access to the bloodstream (Li et al., 2020b; Figure 2). On ensuring access to the systemic circulation, SARSCoV-2 disrupts the endothelial barrier of the BBB or the bloodcerebrospinal fluid barrier (BCSFB) via its interaction with ACE2 receptors at the endothelial cells and subsequent CNS contact (Li et al., 2020b). The presence of SARS-CoV-2 like particles in the neural and frontal lobe capillary endothelial cells of the patient who died with COVID-19 affirmed the hematogenous-endothelial route of SARS-CoV-2 neuroinvasion (Paniz-Mondolfi et al., 2020). Moreover, SARS-CoV-2 was also suggested to cross $\mathrm{BBB}$ by inducing inflammation or hypoxemia by stimulating the release of pro-inflammatory cytokines and chemokines (Li et al., 2020b; Lima et al., 2020). The pro-inflammatory cytokines $v i z$. interferon-gamma (IFN- $\gamma$ ), interleukin (IL)-2, IL-6, IL-8, and tumor necrosis factor-alpha (TNF- $\alpha$ ) were suggested to play a part in SARS-CoV-2 cellular invasion (Achar and Ghosh, 2020). However, it is unclear if induction of these pro-inflammatory cytokines is a result of SARS-CoV-2 cellular invasion activity or it reflects an elicited antiviral immune response for its neutralization/clearance. Multiple clinical reports exhibited a surge in IL-6, IL-10, IL2 , and IFN- $\gamma$ levels in COVID-19 patients that was attributed to an activated neutrophils and leucocytes immune function, but the decline in lymphocyte/T Cell response (Gong et al., 
2020; Huang et al., 2020b; Liu et al., 2020). Therefore, further studies are warranted to elucidate the nature and cause of these elicited pro-inflammatory cytokines in COVID-19 patients and if it has a relation to SARS-CoV-2 immunoinvasive activity.

\section{Neuronal/Nervous System Route}

SARS-CoV-2 particles were primarily suggested to enter the nerve termini and undergo replication before transportation to the soma and ensuring CNS invasion (Li et al., 2020b). Among the potential SARS-CoV-2 neuroinvasion routes, the olfactory tract serves as an important route for respiratory viruses (Meinhardt et al., 2020; Figure 2). Also, the peripheral nerves namely trigeminal and vagus nerves that innervate distinct parts of the respiratory tract were suggested to be the target of SARS-CoV-2 neuroinvasion (Yavarpour-Bali and Ghasemi-Kasman, 2020). SARS-CoV-2 invades the neuralmucosal interface via its transmucosal entry across the nervous assemblies followed by their access to the olfactory tract of the CNS (Meinhardt et al., 2020). Coronaviruses can also invade CNS via a synapse-connected route by infecting the peripheral nerve terminals (Dube et al., 2018; Lima et al., 2020). Dube et al. (2018) earlier claimed that human coronavirus (HCoV OC43) might also actively transport through axonal transport by axoplasmic flow and/or may passively diffuse across this channel. SARS-CoV-2 is believed to enter CNS via trigeminal nerves that innervate nociceptor cells in the nasal fossa; while the sensory terminal of the trigeminal nerves exits in the conjunctiva (Lima et al., 2020). The finding of SARS-CoV-2 RNA fragment in the ocular discharge of a patient with conjunctivitis (Zhang et al., 2020) further suggested trigeminal nerve-mediated entry of SARS-CoV2 to CNS.

\section{Lymphatic-Cerebrospinal Fluid (CSF) Route}

The bronchus and trachea tissues comprise a rich and intricate lymphatic network. The olfactory nerve perineural and nasal lymphatic tissue space is suggested to facilitate the CSF drainage by communicating with the channels constituted by ensheathing cells (Figure 2). Of note, endothelial cells in lymphatic networks express CD209L receptor that was claimed to be another receptor facilitating coronavirus invasion (Li et al., 2007). The presence of SARS-CoV-2 nucleocapsid protein in the cells of lymphoid organs affirmed the functioning of the CSF route in the SARSCoV-2 neuroinvasion (Chen et al., 2020b). These pieces of evidence postulating invasion of CNS by SARS-CoV-2 involve perivascular or lymphatic path as an alternative route (Ylikoski et al., 2020).

\section{Infected Immune/Lymphatic Cells}

Coronaviruses-infected lymphatic/immune cells i.e., $\mathrm{T}$ cells, monocytes, and neutrophils were suggested to serve as reservoirs for the virus and were capable to enter and infect the CNS (Iadecola et al., 2020; Figure 2). These immune cells travel to the brain through the meninges and the choroid plexus vasculature (Engelhardt et al., 2017), which could serve as the entry sites for SARS-CoV-2 infected immune cells. As discussed earlier, immune cells also express ACE2 that serves as the molecular receptor for coronaviruses (Lima et al., 2020). Although presently we lack any direct clinical evidence of SARS-CoV-2 invasion of immune cells (Merad and Martin, 2020), immunoreactivity of CD169+ cells for SARS-CoV-2 nucleocapsid protein was seen in the lymph node splenic marginal zone and marginal sinuses (Chen et al., 2020b). Given the fact that CD169+ macrophages amply express ACE-2, makes them a potential target of SARSCoV-2 neuroinvasion that may further facilitate the entry of infected immune cells to CNS (Park, 2020). Consistent with this, the presence of viral RNA in the macrophages of bronchoalveolar lavage in the COVID-19 patient further highlights the role of infected lymphatic/immune cells in SARS-CoV2 neuroinvasion (Bost et al., 2020). This evidence postulates that SARS-CoV-2 may infect circulating immune cells and could potentially exploit them to disseminate/invade through the CNS (Figure 2). However, it is still unclear if such presence of SARSCoV-2 virions/single strand RNA is due to its macrophage invasion or was a result of active phagocytic uptake of the infected cell or SARS-CoV-2 virion (Bost et al., 2020; Merad and Martin, 2020). In contrast, few clinical autopsy reports from COVID-19 patients showed a lack of any infected immune cell infiltration to CNS (Kantonen et al., 2020; Solomon et al., 2020).

The secretion of interferons is the foremost antiviral defense acquired by the immune cells that also stimulate the neighboring immune cells. Coronaviruses can evade the host immune response by producing severe leukopenia and lymphopenia (Wong et al., 2003; Zaki et al., 2012). Earlier investigations on SARS-CoV and MERS-CoV revealed that coronaviruses encode proteins that modulate downstream regulation of TLRs and the JAK-STAT signaling pathway by interacting with their effectors in immune cells. For instance, SARS-CoV and MERS-CoV encoded protein PLpro, inhibits the NF- $\kappa$ B from I $\kappa \mathrm{B} \alpha$ dissociation, while, SARSCoV's PLpro and ORF3b proteins block IRF3 phosphorylation and its nuclear translocation (Devaraj et al., 2007; Signaling et al., 2009). The role of these viral proteins was also implicated in the inhibition of the JAK-STAT pathway (Menachery et al., 2014). In the case of SARS-CoV-2 infection of immune cells, an overall decline in the transcription of antiviral genes was reported due to decreased Type I and III interferons production and an elevated chemokine secretion (Blanco-Melo et al., 2020). Of note, results from in vivo and ex vivo SARS-CoV-2 experiments affirmed in vitro findings and thereby suggested that a decline in the innate antiviral response with instigated hyper-inflammation, could be a potential mechanism of SARS-CoV-2 invasion of immune cells and may contribute to COVID-19 severity (Blanco-Melo et al., 2020). Apart from reducing the $\mathrm{T}$ cell number, SARS-CoV2 also causes effector $\mathrm{T}$ cell exhaustion as another mechanism to compromise immune cell function (Diao et al., 2020; Zheng et al., 2020). SARS-CoV-2 exhausted effector T cells as a result show elevated levels of inhibitory receptors viz. PD-1, TIM-3, and TIGIT at its surface given the IL-6, IL-10, and TNF- $\alpha$ exposure and declined regulatory T cell function (Chiappelli et al., 2020; Qin et al., 2020). 


\section{POTENTIAL MECHANISMS OF SARS-COV-2 INDUCED NEUROLOGICAL INJURY}

As mentioned, SARS-CoV-2 invasion requires ACE2 for S-protein binding followed by its priming by cell proteases TRMPSS2 (Hoffmann et al., 2020). Recent studies also implicated the role of heparan sulfate at the host cell membrane in facilitating the S-protein and ACE2 binding and viral invasion (Clausen et al., 2020; Kalra and Kandimalla, 2021). Co-expression analysis of ACE2 and TMPRSS2 revealed that nasal goblet, ciliated epithelial cells, and oligodendrocytes ubiquitously express both the proteins (Sardu et al., 2020). More specifically, ACE2-TMPRSS2 co-expression in oligodendrocytes could potentiate CNS infiltration as clinical features of acute encephalitis as observed in COVID-19 patients (Hung et al., 2003; Ding et al., 2004). As discussed in the earlier section, coronaviruses can invade the CNS either by a neuronal or humoral/hematogenous route (Figure 2). Therein, early anosmia, i.e., a primary feature of SARS-CoV-2 neuroinvasion that occurs through the olfactory bulb, whereas a retrograde migration of human coronaviruses to olfactory nerve and the CNS via nasal epithelium was studied in the murine model (Netland et al., 2008). An earlier study reported an eight-fold increase in the frequency of human coronaviruses infected cells in the CNS that was specifically noticeable in the hippocampus post 1-2 weeks of infection (Chan et al., 2020).

An alternative route of CNS entry for coronaviruses is through the $\mathrm{BBB}$ that comprises conditions/factors including endothelins, inflammatory mediators, infected macrophages shipping the virus, or directly infected endothelial cells (Edwards et al., 2000; Paniz-Mondolfi et al., 2020; Sardu et al., 2020). Once the virus reaches the CNS, it starts swift trans-neuronal spread and produces neurotoxicity in infected ACE2-positive neutrons, as validated in transgenic mice models (Netland et al., 2008). Although both SARS-CoV-1 and SARS-CoV-2 bind to ACE2 receptor for host cell entry, recent phylogenetic and virus-receptor binding structural data suggested that SARSCoV-2 recognizes ACE2 more effectively (Wan et al., 2020; $\mathrm{Xu}$ et al., 2020). Therefore, high expression of ACE2 in brain endothelial cells, neurons, and glial cells, makes these neurological cells more prone to SARS-CoV-2 neuroinvasion (Hamming et al., 2004). SARS-CoV-2 recognition of ACE2 may disrupt the delicate balance of ACE-ACE2 cerebrovascular control that could result in incessantly activated ACE signal, severe vasoconstriction, or interrupted cerebral autoregulation. Moreover, SARS-CoV-2 pathogenicity in these tissues was found to elicit IL-1 $\beta,-2,-6,-7,-8,-10,-17$, INF $\gamma$, G-CSF, TNF $\alpha$, MCP1, and macrophage inflammatory protein $1 \alpha$ (Pedersen and Ho, 2020). The triggered levels of these pro-inflammatory factors produce a "cytokine storm" and are known to be associated with poor clinical outcomes. Besides ARDS, cytokine storm produces severe neurotoxicity by compromising the integrity of the $\mathrm{BBB}$, in absence of direct viral transport or neuroinvasion. These features speculated that acute necrotizing encephalopathy (ANE), may essentially be produced by cytokine-induced neurotoxicity (Ouattara et al., 2011). Therefore, cytokineinduced neurotoxicity in SARS-CoV-2 infected patients may upset neurologic outcomes (Allan and Rothwell, 2001).

Among the different age groups of COVID-19 patients admitted to the hospital, the aforementioned neurological mechanisms were severely deregulated in the elderly population and have exposed their vulnerability (reviewed by COVIDview, 2020; Lekamwasam and Lekamwasam, 2020). These mechanisms of neurological complications underlined the role of disrupted immune function or cytokine-induced neurotoxicity in elderly COVID-19 patients. Koff and Williams (2020) reviewed the consequence of diminished immunity in the aging population and how COVID-19 took advantage of it to exploit it further (Koff and Williams, 2020).

\section{EMERGING ROLE OF ARTIFICIAL INTELLIGENCE AND MACHINE LEARNING IN COVID-19 DIAGNOSTICS}

During this COVID-19 pandemic, hospitals and other healthcare services have experienced severe crises and are opening up to technologies that can be used in clinical settings as a support system for the frontline healthcare workers in the detection and containment of such diseases. AI is one of those technologies with long-term value. Not only diagnostics but $\mathrm{AI}$ is also being employed in hospitals to handle the rapidly increasing load of patients. To manage a similar situation in Boston, Partners HealthCare came up with a hotline service for patients, clinicians, and others with concerns related to COVID-19. The main aim of this initiative was: (i) to identify the class of people with mild symptoms who did not need additional care, to provide them with relevant information and direct them to relevant virtual care options; (ii) to manage the small high-risk patients by linking them to testing sites, newly created respiratory illness clinics, or emergency department of hospitals in case necessary. This initiative was further expanded in collaboration with St. Joseph Health system in Seattle and Microsoft, which served more than 40,000 patients in the 1st week itself. In line with this, smart AI bots are also being developed as chatbots to manage the increasing needs of patients and clinicians. Moving a step ahead, a group of researchers at MIT has trained an AI model that can distinguish asymptomatic people from healthy individuals through their forced-cough recordings. The model was able to accurately detect $98.5 \%$ of COVID-19 positive people, which included 100\% cases of coughs submitted by asymptomatic patients (Laguarta et al., 2020). Though still in its infancy, such technology can be used as a pre-screening tool in various situations. Another group has reported an AI-based screening model for early detection of COVID-19 using the routinely collected healthcare data (laboratory tests, blood gas measurements, and vital signs) that typically become available within the first hour of presentation to any hospital with regular laboratory infrastructure (Soltan et al., 2020). During the 2 weeks of testing phase at the John Radcliffe Hospital in Oxford and 
the Horton General Hospital in Banbury, this AI model could correctly predict the COVID-19 status of $92.3 \%$ of patients admitted to the emergency departments. So, as an alternative to the swab test that takes typically a day's time for results, this AI screening maintained the flow through the hospital by confidently predicting the negative COVID-19 cases. Several governments and hospitals across the globe are also using AI-powered sensors to identify suspected patients. Of note, physician-researchers at Brigham and Women's Hospital and Massachusetts General Hospital are trying to make use of intelligent robots (developed at Boston Dynamics and MIT) to monitor vital signs in COVID-19 patients and deliver their medications (Wittbold et al., 2020). This will assure the least human contact with infected patients and thus control disease transmission.

Scaling AI for better explainability and transparency of imaging for diagnostics is another major direction to improve upon. An AI algorithm has also been constituted that integrates a spectrum of chest CT imaging features with clinical symptoms, exposure history, and laboratory testing to rapidly diagnose COVID-19 positive patients. The trained model was able to achieve an Area under the ROC Curve (AUC) of 0.92, indicating a sensitivity comparable to that of a senior thoracic radiologist. It was also able to detect 17 out of 25 COVID-19 positive patients, who were reported as negative by the radiologists (Mei et al., 2020). Jin et al. (2020) have also reported a similar model that makes use of chest CTs for COVID-19 detection. In China, an AI-driven CT scan interpreter has been installed in Zhongnan Hospital that helps in the diagnosis of COVID-19 when radiologists are not available (Wittbold et al., 2020). Furthermore, this technology can have direct implications in the detection of post-COVID-19 neurological complications as well. For example, AI could have been efficiently used in the study to systematically characterize neurological symptoms in COVID-19 infected people that involved neuroimaging of about 108 patients from multiple institutions in Italy (Mahammedi et al., 2020). AI thus holds the promising potential to develop into a mainstream diagnostic for fast and efficient detection of various diseases.

Although AI seems to be a promising solution to our growing healthcare needs, it needs to be executed with human clinical expert decision-making at appropriate levels to ensure high quality and safe delivery of AI outcomes. AI can only be an aid but cannot be a replacement for human clinical reasoning and decision making.

\section{CONCLUSION}

Emerging clinical data revealed that neurologic manifestations are frequent in elderly and severely sick COVID-19 patients that significantly raised their mortality. Also, existing comorbidities in COVID-19 patients can further contribute to the neurological complications and impact the clinical outcome. Existing neurological conditions, neurodegenerative ailments, and inflammation in the elderly population were found to worsen the clinical outcome in COVID-19 patients. Although emerging clinical evidence underlined the role of neuroinvasion, neuroinflammation, immunopathogenesis, and hypoxemia in the development of CNS manifestations, the molecular mechanism of COVID-19 neurotoxicity is not yet completely known. Therefore, direct involvement of the above events during or post-SARS-CoV-2 infection is unclear to assess their exact clinical outcomes in elderly COVID-19 patients. Given the diverse and complex clinical signatures of COVID-19 affecting multiple cross-histological functions, it warrants more concerted efforts to distinctly characterize the molecular events involved in its pathogenesis, more importantly in elderly patients. Clinical data revealing SARS-CoV-2 presence in the brain postulated neuroinvasion theory, therefore, direct contact of SARS-CoV-2 with the nervous system is clinically relevant. However, the lack of SARS-CoV-2 virion/mRNA in CSF in the majority of the COVID-19 cases hinted at an alternative viral gateway. Also, in COVID-19 patients, SARS$\mathrm{CoV}$-2-induced inflammation and immune response appeared to further exacerbate the neurologic complications. Given the fact that COVID-19 infection severity has a direct link with the extent of inflammation, the possibility of deregulated immune function in neurotoxicity cannot be excluded. Incidences of "cytokine storm" in SARS-CoV-2 infected patients are seen to greatly contribute to neurological complications, more often in elderly patients. Therefore, in the COVID-19 patients, virus-induced inflammation is suggested to play a key role in potentiating neurological complications. However, it requires further investigation at the molecular and systemic level to precisely define the pathophysiological relevance of these events in neurological complications.

SARS-CoV-2 infected elderly patients are at higher risk of neurological complications. These complications beyond producing acute illness can also exert prolong impact on the functioning of the nervous system. These facts made aged COVID-19 patient's health management more complex, even greater for those having preexisting comorbidities. Careful assessment of these features in admitted elderly COVID-19 patients with the help of advanced AI and machine learning can make COVID-19 diagnostics more efficient and could also save lives. Conclusively, COVID-19 associated neurological complications are a serious health concern and require more concerted investigative efforts to understand and intervene in their progression in elderly patients.

\section{AUTHOR CONTRIBUTIONS}

RSK, JKD, and RK conceived the idea. RSK, JKD, AM, VK, BS, SDa, SDe, and RK wrote the manuscript. RSK drafted the manuscript figures. RSK, JKD, BS, and RK supervised and critically revised the study. All authors contributed to the article and approved the submitted version.

\section{FUNDING}

RK acknowledges DBT for Ramalingaswami Re-entry Fellowship (No. BT/RLF/Re-entry/22/2016 and SAN.No. 102/IFD/SAN/1117/2018-19) and CSIR IICT, Hyderabad, India. 


\section{REFERENCES}

Abdi, S., Ghorbani, A., and Fatehi, F. (2020). The association of SARS-CoV2 infection and acute disseminated encephalomyelitis without prominent clinical pulmonary symptoms. J. Neurol. Sci. 416:117001. doi: 10.1016/j.jns. 2020.117001

Achar, A., and Ghosh, C. (2020). COVID-19-associated neurological disorders: the potential route of cns invasion and blood-brain relevance. Cells 9:2360. doi: $10.3390 /$ cells 9112360

Agrawal, L., Poullikkas, T., Eisenhower, S., Monsanto, C., Bakku, R. K., and Chen, M. H. (2021). Viroinformatics-based analysis of SARS$\mathrm{CoV}-2$ core proteins for potential therapeutic targets. Antibodies 10:3. doi: 10.3390/antib10010003

Alghatrif, M., Cingolani, O., and Lakatta, E. G. (2020). The dilemma of coronavirus disease 2019, aging and cardiovascular disease: insights from cardiovascular aging science. JAMA Cardiol. 5, 747-748. doi: 10.1001/jamacardio.2020.1329

Allan, S. M., and Rothwell, N. J. (2001). Cytokines and acute neurodegeneration. Nat. Rev. Neurosci. 2, 734-744. doi: 10.1038/35094583

Alrubaye, R., and Choudhury, H. (2020). Severe rhabdomyolysis in a 35-yearold woman with COVID-19 due to SARS-CoV-2 infection: a case report. Am. J. Case Rep. 21:e926733. doi: 10.12659/AJCR.926733

Al Saiegh, F., Ghosh, R., Leibold, A., Avery, M. B., Schmidt, R. F., Theofanis, T., et al. (2020). Status of SARS-CoV-2 in cerebrospinal fluid of patients with COVID-19 and stroke. J. Neurol. Neurosurg. Psychiatry 91, 846-848. doi: 10.1136/jnnp-2020-323522

Avula, A., Nalleballe, K., Narula, N., Sapozhnikov, S., Dandu, V., Toom, S., et al. (2020). COVID-19 presenting as stroke. Brain. Behav. Immun. 87, 115-119. doi: 10.1016/j.bbi.2020.04.077

Beghi, E., Feigin, V., Caso, V., Santalucia, P., and Logroscino, G. (2020). COVID19 infection and neurological complications: present findings and future predictions. Neuroepidemiology 54, 364-369. doi: 10.1159/000508991

Belluck, P. (2020). Nearly One-third of Covid-19 Patients in Study had Altered Mental State. The New York Times. Available online at: https://www. nytimes.com/2020/10/05/health/Covid-patients-mental-state.html. Accessed December 28, 2020

Berger, J.R., Brandstadter, R., and Bar-Or, A. (2020). COVID-19 and MS disease-modifying therapies. Neurol. Neuroimmunol. Neuroinflamm. 7:e761. doi: 10.1212/NXI.0000000000000761

Beyrouti, R., Adams, M. E., Benjamin, L., Cohen, H., Farmer, S. F., Goh, Y. Y., et al. (2020). Characteristics of ischaemic stroke associated with COVID19. J. Neurol. Neurosurg. Psychiatry 91, 889-891. doi: 10.1136/jnnp-2020323586

Blanco-Melo, D., Nilsson-payant, B. E., Liu, W., Uhl, S., Hoagland, D., Møller, R., et al. (2020). Imbalanced host response to SARS-CoV-2 drives development of COVID-19. Cell 181, 1036-1045. doi: 10.1016/j.cell.2020.04.026

Bo, H. X., Li, W., Yang, Y., Wang, Y., Zhang, Q., Cheung, T., et al. (2020). Posttraumatic stress symptoms and attitude toward crisis mental health services among clinically stable patients with COVID-19 in China. Psychol. Med. 1-2. doi: 10.1017/S0033291720000999. [Online ahead of print].

Bost, P., Giladi, A., Liu, Y., Bendjelal, Y., Xu, G., David, E., et al. (2020). Hostviral infection maps reveal signatures of severe COVID-19 patients. Cell 181, 1475.e12-1488.e12. doi: 10.1016/j.cell.2020.05.006

Bsteh, G., Bitschnau, C., Hegen, H., Auer, M., Di Pauli, F., Rommer, P., et al. (2020). Multiple sclerosis and COVID-19: how many are at risk? Eur. J. Neurol. doi: 10.1111/ene.14555 [Epub ahead of print].

Camdessanche, J. P., Morel, J., Pozzetto, B., Paul, S., Tholance, Y., and BotelhoNevers, E. (2020). COVID-19 may induce Guillain-Barre syndrome. Rev. Neurol. 176, 516-518. doi: 10.1016/j.neurol.2020.04.003

Chan, J. F., Kok, K. H., Zhu, Z., Chu, H., To, K. K., Yuan, S., et al. (2020). Genomic characterization of the 2019 novel human-pathogenic coronavirus isolated from a patient with atypical pneumonia after visiting Wuhan. Emerg. Microbes. Infect. 9, 221-236. doi: 10.1080/22221751.2020.1719902

Chan, K. S., Zheng, J. P., Mok, Y. W., Li, Y. M., Liu, Y. N., Chu, C. M., et al. (2003). SARS: prognosis, outcome and sequelae. Respirology 8, S36-S40. doi: 10.1046/j. 1440-1843.2003.00522.x

Chen, T., Wu, D., Chen, H., Yan, W., Yang, D., Chen, G., et al. (2020a). Clinical characteristics of 113 deceased patients with coronavirus disease 2019: retrospective study. BMJ 368:m1091. doi: 10.1136/bmj.m1295
Chen, Y., Feng, Z., Diao, B., Wang, R., Wang, G., and Wang, C. (2020b). The novel severe acute respiratory syndrome Coronavirus 2 (SARS-CoV2) directly decimates human spleens and lymph nodes. MedRxiv [Preprint]. doi: 10.1101/2020.03.27.20045427

Chiappelli, F., Khakshooy, A., and Greenberg, G. (2020). COVID19 immunopathology \& immunotherapy. Bioinformation 16, 219-222. doi: $10.6026 / 97320630016219$

Clausen, T. M., Sandoval, D. R., Spliid, C. B., Pihl, J., Perrett, H. R., and Painter, C. D. (2020). SARS-CoV-2 infection depends on cellular heparan sulfate and ACE2. Cell 183, 1043.e15-1057.e15.doi: 10.1016/j.cell.2020.09.033

COVIDview. (2020). A weekly surveillance summary of US COVID-19 activity. Key updates for week, 29. Available online at: https://www.cdc.gov/ coronavirus/2019-ncov/covid-data/pdf/covidview-07-24-2020.pdf. Accessed July $28,2020$.

Devaraj, S. G., Wang, N., Chen, Z., Chen, Z., Tseng, M., Barretto, N., et al. (2007). Regulation of IRF-3-dependent innate immunity by the papain-like protease domain of the severe acute respiratory syndrome coronavirus. J. Biol. Chem. 282, 32208-32221. doi: 10.1074/jbc.M704870200

Diao, B., Wang, C., Tan, Y., Chen, X., Liu, Y., Ning, L., et al. (2020). Reduction and functional exhaustion of $\mathrm{T}$ cells in patients with coronavirus disease 2019 (COVID-19). Front. Immunol. 11:827. doi: 10.3389/fimmu.2020. 00827

Ding, Y., He, L., Zhang, Q., Huang, Z., Che, X., Hou, J., et al. (2004). Organ distribution of severe acute respiratory syndrome (SARS) associated coronavirus (SARS-CoV) in SARS patients: implications for pathogenesis and virus transmission pathways. J. Pathol. 203, 622-630. doi: 10.1002/path. 1560

Dinkin, M., Gao, V., Kahan, J., Bobker, S., Simonetto, M., Wechsler, P., et al. (2020). COVID-19 presenting with ophthalmoparesis from cranial nerve palsy. Neurology 95, 221-223. doi: 10.1212/WNL.0000000000009700

Dube, M., Le Coupanec, A., Wong, A. H. M., Rini, J. M., Desforges, M., and Talbot, P. J. (2018). Axonal transport enables neuron-to-neuron propagation of human Coronavirus OC43. J. Virol. 92, e00404-e00418. doi: 10.1128/JVI. 00404-18

Edwards, J. A., Denis, F., and Talbot, P. J. (2000). Activation of glial cells by human coronavirus OC43 infection. J. Neuroimmunol. 108, 73-81. doi: 10.1016/s01655728(00)00266-6

Efe, I. E., Aydin, O. U., Alabulut, A., Celik, O., and Aydin, K. (2020). COVID-19associated encephalitis mimicking glial tumor. World Neurosurg. 140, 46-48. doi: 10.1016/j.wneu.2020.05.194

Ellul, M. A., Benjamin, L., Singh, B., Lant, S., Michael, B. D., Easton, A., et al. (2020). Neurological associations of COVID-19. Lancet Neurol. 19, 767-783. doi: 10.1016/S1474-4422(20)30221-0

Engelhardt, B., Vajkoczy, P., and Weller, R. O. (2017). The movers and shapers in immune privilege of the CNS. Nat. Immunol. 18, 123-131. doi: 10.1038/ ni.3666

Farhadian, S., Glick, L. R., Vogels, C. B. F., Thomas, J., Chiarella, J., Casanovas-Massana, A., et al. (2020). Acute encephalopathy with elevated CSF inflammatory markers as the initial presentation of COVID-19. BMC Neurol. 20:248. doi: 10.1186/s12883-020-01812-2

Fotuhi, M., Mian, A., Meysami, S., and Raji, C. A. (2020). Neurobiology of COVID-19. J. Alzheimers Dis. 76, 3-19. doi: 10.3233/JAD-200581

Frontera, J. A., Sabadia, S., Lalchan, R., Fang, T., Flusty, B., and MillarVernetti, P. (2021). A prospective study of neurologic disorders in hospitalized patients with COVID-19 in New York City. Neurology 96, e575-e586. doi: 10.1212/WNL.0000000000010979

Giovannoni, G., Hawkes, C., Lechner-Scott, J., Levy, M., Waubant, E., and Gold, J. (2020). The COVID-19 pandemic and the use of MS disease-modifying therapies. Mult. Scler. Relat. Disord. 39:102073. doi: 10.1016/j.msard.2020. 102073

Goertz, Y. M. J., Van Herck, M., Delbressine, J. M., Vaes, A. W., Meys, R., Machado, F. V. C., et al. (2020). Persistent symptoms 3 months after a SARSCoV-2 infection: the post-COVID-19 syndrome? ERJ Open Res. 6, 00542-2020. doi: $10.1183 / 23120541.00542-2020$

Gong, J., Dong, H., Xia, S. Q., Huang, Y. Z., Wang, D., Zhao, Y., et al. (2020). Correlation analysis between disease severity and inflammation-related parameters in patients with COVID-19 pneumonia. MedRxiv [Preprint]. doi: 10.1101/2020.02.25.20025643 
Guan, W. J., Ni, Z. Y., Hu, Y., Liang, W. H., Ou, C. Q., He, J. X., et al. (2020). Clinical characteristics of Coronavirus disease 2019 in China. N. Engl. J. Med. 382, 1708-1720. doi: 10.1056/NEJMoa2002032

Gutierrez-Ortiz, C., Mendez-Guerrero, A., Rodrigo-Rey, S., San Pedro-Murillo, E., Bermejo-Guerrero, L., Gordo-Manas, R., et al. (2020). Miller Fisher syndrome and polyneuritis cranialis in COVID-19. Neurology 95, e601-e605. doi: 10.1212/WNL.0000000000009619

Halpin, S. J., Mcivor, C., Whyatt, G., Adams, A., Harvey, O., Mclean, L., et al. (2021). Postdischarge symptoms and rehabilitation needs in survivors of COVID-19 infection: a cross-sectional evaluation. J. Med. Virol. 93, 1013-1022. doi: 10.1002/jmv.26368

Hamming, I., Timens, W., Bulthuis, M. L., Lely, A. T., Navis, G., and van Goor, H. (2004). Tissue distribution of ACE2 protein, the functional receptor for SARS coronavirus. A first step in understanding SARS pathogenesis. J. Pathol. 203, 631-637. doi: 10.1002/path.1570

Hanafi, R., Roger, P. A., Perin, B., Kuchcinski, G., Deleval, N., Dallery, F., et al. (2020). COVID-19 neurologic complication with CNS vasculitis-like pattern. Am. J. Neuroradiol. 41, 1384-1387. doi: 10.3174/ajnr.A6651

Hayashi, M., Sahashi, Y., Baba, Y., Okura, H., and Shimohata, T. (2020). COVID19-associated mild encephalitis/encephalopathy with a reversible splenial lesion. J. Neurol. Sci. 415:116941. doi: 10.1016/j.jns.2020.116941

Helms, J., Kremer, S., Merdji, H., Clere-Jehl, R., Schenck, M., Kummerlen, C., et al. (2020). Neurologic features in severe SARS-CoV-2 infection. N. Engl. J. Med. 382, 2268-2270. doi: 10.1056/NEJMc2008597

Herman, C., Mayer, K., and Sarwal, A. (2020). Scoping review of prevalence of neurologic comorbidities in patients hospitalized for COVID-19. Neurology 95 , 77-84. doi: 10.1212/WNL.0000000000009673

Hoffmann, M., Kleine-Weber, H., Schroeder, S., Kruger, N., Herrler, T., Erichsen, S., et al. (2020). SARS-CoV-2 cell entry depends on ACE2 and TMPRSS2 and is blocked by a clinically proven protease inhibitor. Cell 181, 271.e278-280.e278.doi: 10.1016/j.cell.2020.02.052

Huang, C. F., Tay, C. K., Zhuang, Y. F., Liu, J., and Sewa, D. W. (2020a). Rationale and significance of patient selection in awake prone positioning for COVID-19 pneumonia. Eur. Respir. J. 56:2002173. doi: 10.1183/13993003.021 73-2020

Huang, C., Wan, Y., Li, X., Ren, L., Zhao, J., and Hu, Y. (2020b). Clinical features of patients infected with 2019 novel coronavirus in Wuhan, China. Lancet 395, 497-506. doi: 10.1016/S0140-6736(20)30183-5

Hung, E. C., Chim, S. S., Chan, P. K., Tong, Y. K., Ng, E. K., Chiu, R. W., et al. (2003). Detection of SARS coronavirus RNA in the cerebrospinal fluid of a patient with severe acute respiratory syndrome. Clin. Chem. 49, 2108-2109. doi: 10.1373/clinchem.2003.025437

Iadecola, C., Anrather, J., and Kamel, H. (2020). Effects of COVID-19 on the nervous system. Cell 183, 16.e11-27.e11. doi: 10.1016/j.cell.2020.08.028

Jin, M., and Tong, Q. (2020). Rhabdomyolysis as potential late complication associated with COVID-19. Emerg. Infect. Dis. 26, 1618-1620. doi: 10.3201/eid2607.200445

Jin, C., Chen, W., Cao, Y., Xu, Z., Tan, Z., Zhang, X., et al. (2020). Development and evaluation of an artificial intelligence system for COVID-19 diagnosis. Nat. Commun. 11:5088. doi: 10.1038/s41467-020-18685-1

Kalra, R. S., and Kandimalla, R. (2021). Engaging the spikes: heparan sulfate facilitates SARS-CoV-2 spike protein binding to ACE2 and potentiates viral infection. Signal Transduct. Target Ther. 6:39. doi: 10.1038/s41392-021 -00470-1

Kalra, R. S., Kumar, V., Dhanjal, J. K., Garg, S., Li, X., Kaul, S. C., et al. (2021). COVID19-inhibitory activity of withanolides involves targeting of the host cell surface receptor ACE2: insights from computational and biochemical assays. J. Biomol. Struct. Dyn. 2, 1-14. doi: 10.1080/07391102.2021.1902858

Kalra, R. S., Tomar, D., Meena, A. S., and Kandimalla, R. (2020). SARSCoV-2, ACE2 and hydroxychloroquine: cardiovascular complications, therapeutics and clinical readouts in the current settings. Pathogens 9:546. doi: 10.3390/pathogens 9070546

Kandemirli, S. G., Dogan, L., Sarikaya, Z. T., Kara, S., Akinci, C., Kaya, D., et al. (2020). Brain MRI findings in patients in the intensive care unit with COVID-19 infection. Radiology 297, E232-E235. doi: 10.1148/radiol. 2020201697

Kantonen, J., Mahzabin, S., Mäyränpää, M. I., Tynninen, O., Paetau, A., Andersson, N., et al. (2020). Neuropathologic features of four autopsied
COVID-19 patients. Brain Pathol. 30, 1012-1016. doi: 10.1111/bpa. 12889

Klok, F. A., Kruip, M., Van Der Meer, N. J. M., Arbous, M. S., Gommers, D., Kant, K. M., et al. (2020). Incidence of thrombotic complications in critically ill ICU patients with COVID-19. Thromb. Res. 191, 145-147. doi: 10.1016/j. thromres.2020.04.013

Koff, W. C., and Williams, M. A. (2020). Covid-19 and immunity in aging populations-a new research agenda. N. Engl. J. Med. 383, 804-805. doi: 10.1056/NEJMp2006761

Laguarta, J., Hueto, F., and Subirana, B. (2020). COVID-19 artificial intelligence diagnosis using only cough recordings. IEEE Open J. Eng. Med. Biol. 1, 275-281. doi: $10.2196 / 21801$

Lechien, J. R., Chiesa-Estomba, C. M., De Siati, D. R., Horoi, M., Le Bon, S. D., Rodriguez, A., et al. (2020a). Olfactory and gustatory dysfunctions as a clinical presentation of mild-to-moderate forms of the coronavirus disease (COVID-19): a multicenter European study. Eur. Arch. Otorhinolaryngol. 277, 2251-2261. doi: 10.1007/s00405-020-05965-1

Lechien, J. R., Chiesa-Estomba, C. M., Vaira, L. A., Saussez, S., and Hans, S. (2020b). COVID-19 reinfection and second episodes of olfactory and gustatory dysfunctions: report of first cases. Ear Nose Throat J. doi: 10.1177/0145561320970105. [Online ahead of print].

Lee, S. M., Kang, W. S., Cho, A. R., Kim, T., and Park, J. K. (2018). Psychological impact of the 2015 MERS outbreak on hospital workers and quarantined hemodialysis patients. Compr. Psychiatry 87, 123-127. doi: 10.1016/j.comppsych.2018.10.003

Lee, J. W., Ko, J., Ju, C., and Eltzschig, H. K. (2019). Hypoxia signaling in human diseases and therapeutic targets. Exp. Mol. Med. 51, 1-13. doi: 10.1038/s12276019-0235-1

Lekamwasam, R., and Lekamwasam, S. (2020). Effects of COVID-19 pandemic on health and wellbeing of older people: a comprehensive review. Ann. Geriatr. Med. Res. 24, 166-172. doi: 10.4235/agmr.20.0027

Lennon, J. C. (2020). Neurologic and immunologic complications of COVID-19: potential long-term risk factors for Alzheimer's disease. J. Alzheimers Dis. Rep. 4, 217-221. doi: 10.3233/ADR-200190

Li, J., Gao, J., Xu, Y. P., Zhou, T. L., Jin, Y. Y., and Lou, J. N. (2007). [Expression of severe acute respiratory syndrome coronavirus receptors, ACE2 and CD209L in different organ derived microvascular endothelial cells]. Zhonghua Yi Xue Za Zhi 87, 833-837.

Li, L., Gao, R., Yu, Y., Kaul, Z., Wang, J., Kalra, R. S., et al. (2018). Tumor suppressor activity of miR-451: identification of CARF as a new target. Sci. Rep. 8:375. doi: 10.1038/s41598-017-18559-5

Li, Y., Li, M., Wang, M., Zhou, Y., Chang, J., Xian, Y., et al. (2020a). Acute cerebrovascular disease following COVID-19: a single center, retrospective, observational study. Stroke Vasc. Neurol. 5, 279-284. doi: 10.1136/svn-2020000431

Li, Z., Liu, T., Yang, N., Han, D., Mi, X., Li, Y., et al. (2020b). Neurological manifestations of patients with COVID-19: potential routes of SARS-CoV2 neuroinvasion from the periphery to the brain. Front. Med. 14, 533-541. doi: 10.1007/s11684-020-0786-5

Lima, M., Siokas, V., Aloizou, A. M., Liampas, I., Mentis, A. A., Tsouris, Z., et al. (2020). Unraveling the possible routes of SARS-COV-2 invasion into the central nervous system. Curr. Treat. Options Neurol. 22:37. doi: 10.1007/s11940-020-00647-z

Liotta, E. M., Batra, A., Clark, J. R., Shlobin, N. A., Hoffman, S. C., Orban, Z. S., et al. (2020). Frequent neurologic manifestations and encephalopathyassociated morbidity in Covid-19 patients. Ann. Clin. Transl. Neurol. 7, 2221-2230. doi: 10.1002/acn3.51210

Liu, J., Li, S., Liu, J., Liang, B., Wang, X., Wang, H., et al. (2020). Longitudinal characteristics of lymphocyte responses and cytokine profiles in the peripheral blood of SARS-CoV-2 infected patients. EBioMedicine 55:102763. doi: 10.1016/j.ebiom.2020.102763

Lu, L., Xiong, W., Liu, D., Liu, J., Yang, D., Li, N., et al. (2020). New onset acute symptomatic seizure and risk factors in coronavirus disease 2019: a retrospective multicenter study. Epilepsia 61, e49-e53. doi: 10.1111/epi.16524

Maas, M. B., Kim, M., Malkani, R. G., Abbott, S. M., and Zee, P. C. (2021). Response to the letter to the editor for "obstructive sleep apnea and risk of COVID-19 infection, hospitalization and respiratory failure". Sleep Breath. doi: 10.1007/s11325-020-02272-1. [Online ahead of print]. 
Mahammedi, A., Saba, L., Vagal, A., Leali, M., Rossi, A., Gaskill, M., et al. (2020). Imaging of neurologic disease in hospitalized patients with COVID19: An italian multicenter retrospective observational study. Radiology 297, E270-E273. doi: 10.1148/radiol.2020201933

Mao, L., Jin, H., Wang, M., Hu, Y., Chen, S., He, Q., et al. (2020). Neurologic manifestations of hospitalized patients with Coronavirus disease 2019 in Wuhan, China. JAMA Neurol. 77, 683-690. doi: 10.1001/jamaneurol. 2020.1127

Marrie, R. A., Cohen, J., Stuve, O., Trojano, M., Sorensen, P. S., Reingold, S., et al. (2015a). A systematic review of the incidence and prevalence of comorbidity in multiple sclerosis: overview. Mult. Scler. 21, 263-281. doi: 10.1177/1352458514564491

Marrie, R. A., Reider, N., Cohen, J., Stuve, O., Trojano, M., Cutter, G., et al. (2015b). A systematic review of the incidence and prevalence of cardiac, cerebrovascular and peripheral vascular disease in multiple sclerosis. Mult. Scler. 21, 318-331. doi: 10.1177/1352458514564485

Martin-Jimenez, P., Munoz-Garcia, M. I., Seoane, D., Roca-Rodriguez, L., Garcia-Reyne, A., Lalueza, A., et al. (2020). Cognitive impairment is a common comorbidity in deceased COVID-19 patients: a hospital-based retrospective cohort study. J. Alzheimers Dis. 78, 1367-1372. doi: 10.3233/JAD200937

Mei, X., Lee, H. C., Diao, K., Huang, M., Lin, B., Liu, C., et al. (2020). Artificial intelligence-enabled rapid diagnosis of COVID-19 patients. Nat. Med. 26, 1224-1228. doi: 10.1038/s41591-020-0931-3

Meinhardt, J., Radke, J., Dittmayer, C., Franz, J., Thomas, C., Mothes, R., et al. (2020). Olfactory transmucosal SARS-CoV-2 invasion as a port of central nervous system entry in individuals with COVID-19. Nat. Neurosci. 24, 168-175. doi: 10.1038/s41593-020-00758-5

Menachery, V. D., Eisfeld, A. J., Schäfer, A., Josset, L., Sims, A. C., Proll, S., et al. (2014). Pathogenic influenza viruses and coronaviruses utilize similar and contrasting approaches to control interferon-stimulated gene responses. MBio 5, 1-11. doi: 10.1128/mBio.01174-14

Merad, M. D., and Martin, J. C. (2020). Pathological inflammation in patients with COVID-19: a key role for monocytes and macrophages. Nat. Rev. Immunol. 20, 355-362. doi: 10.1038/s41577-020-0331-4

Merkler, A. E., Parikh, N. S., Mir, S., Gupta, A., Kamel, H., Lin, E., et al. (2020). Risk of ischemic stroke in patients with Coronavirus Disease 2019 (COVID19) vs patients with influenza. JAMA Neurol. 77, 1-7. doi: 10.1001/jamaneurol. 2020.2730

Minden, S. L., Frankel, D., Hadden, L. S., Srinath, K. P., and Perloff, J. N. (2004). Disability in elderly people with multiple sclerosis: an analysis of baseline data from the sonya slifka longitudinal multiple sclerosis study. NeuroRehabilitation $19,55-67$.

Moein, S. T., Hashemian, S. M., Tabarsi, P., and Doty, R. L. (2020). Prevalence and reversibility of smell dysfunction measured psychophysically in a cohort of COVID-19 patients. Int. Forum Allergy Rhinol. 10, 1127-1135. doi: 10.1002/alr. 22680

Montagne, A., Barnes, S. R., Sweeney, M. D., Halliday, M. R., Sagare, A. P., Zhao, Z., et al. (2015). Blood-brain barrier breakdown in the aging human hippocampus. Neuron 85, 296-302. doi: 10.1016/j.neuron.2014. 12.032

Montalvan, V., Lee, J., Bueso, T., De Toledo, J., and Rivas, K. (2020). Neurological manifestations of COVID-19 and other coronavirus infections: a systematic review. Clin. Neurol. Neurosurg. 194:105921. doi: 10.1016/j.clineuro.2020. 105921

Morassi, M., Bagatto, D., Cobelli, M., D’agostini, S., Gigli, G. L., Bna, C., et al. (2020). Stroke in patients with SARS-CoV-2 infection: case series. J. Neurol. 267, 2185-2192. doi: 10.1007/s00415-020-09885-2

Moriguchi, T., Harii, N., Goto, J., Harada, D., Sugawara, H., Takamino, J., et al. (2020). A first case of meningitis/encephalitis associated with SARS-Coronavirus-2. Int. J. Infect. Dis. 94, 55-58. doi: 10.1016/j.ijid.2020. 03.062

Nath, A. (2020). Neurologic complications of coronavirus infections. Neurology 94, 809-810. doi: 10.1212/WNL.0000000000009455

Netland, J., Meyerholz, D. K., Moore, S., Cassell, M., and Perlman, S. (2008). Severe acute respiratory syndrome coronavirus infection causes neuronal death in the absence of encephalitis in mice transgenic for human ACE2. J. Virol. 82, 7264-7275. doi: 10.1128/JVI.00737-08
Novi, G., Rossi, T., Pedemonte, E., Saitta, L., Rolla, C., Roccatagliata, L., et al. (2020). Acute disseminated encephalomyelitis after SARS-CoV2 infection. Neurol. Neuroimmunol. Neuroinflamm. 7:e797. doi: 10.1212/NXI. 0000000000000797

Ouattara, L. A., Barin, F., Barthez, M. A., Bonnaud, B., Roingeard, P., Goudeau, A., et al. (2011). Novel human reovirus isolated from children with acute necrotizing encephalopathy. Emerg. Infect. Dis. 17, 1436-1444. doi: 10.3201/eid1708.101528

Oxley, T. J., Mocco, J., Majidi, S., Kellner, C. P., Shoirah, H., Singh, I. P., et al. (2020). Large-vessel stroke as a presenting feature of Covid-19 in the young. $N$. Engl. J. Med. 382:e60. doi: 10.1056/NEJMc2009787

Pajo, A. T., Espiritu, A. I., Apor, A., and \& Jamora, R. (2021). Neuropathologic findings of patients with COVID-19: a systematic review. Neurol. Sci. 42, 1255-1266. doi: 10.1007/s10072-021-05068-7

Palao, M., Fernández-Díaz, E., Gracia-Gil, J., Romero-Sánchez, C. M., DíazMaroto, I., and Segura, T. (2020). Multiple sclerosis following SARS-CoV2 infection. Mult. Scler. Relat. Disord. 45:102377. doi: 10.1016/j.msard.2020. 102377

Paniz-Mondolfi, A., Bryce, C., Grimes, Z., Gordon, R. E., Reidy, J., Lednicky, J., et al. (2020). Central nervous system involvement by severe acute respiratory syndrome coronavirus-2 (SARS-CoV-2). J. Med. Virol. 92, 699-702. doi: 10.1002/jmv.25915

Park, M. D. (2020). Macrophages: a trojan horse in COVID-19? Nat. Rev. Immunol. 20:351. doi: 10.1038/s41577-020-0317-2

Parrotta, E., Kister, I., Charvet, L., Sammarco, C., Saha, V., Charlson, R. E., et al. (2020). COVID-19 outcomes in MS: observational study of early experience from NYU multiple sclerosis comprehensive care center. Neurol. Neuroimmunol. Neuroinflamm. 7:e835. doi: 10.1212/NXI.00000000000 00835

Parsons, T., Banks, S., Bae, C., Gelber, J., Alahmadi, H., and Tichauer, M. (2020). COVID-19-associated acute disseminated encephalomyelitis (ADEM). J. Neurol. 267, 2799-2802. doi: 10.1007/s00415-020-09951-9

Pascual-Goni, E., Fortea, J., Martinez-Domeno, A., Rabella, N., Tecame, M., Gomez-Oliva, C., et al. (2020). COVID-19-associated ophthalmoparesis and hypothalamic involvement. Neurol. Neuroimmunol. Neuroinflamm. 7:e823. doi: 10.1212/NXI.0000000000000823

Pavel, A., Murray, D. K., and Stoessl, A. J. (2020). COVID-19 and selective vulnerability to Parkinson's disease. Lancet Neurol. 19:719. doi: 10.1016/S14744422(20)30269-6

Pedersen, S. F., and Ho, Y. C. (2020). SARS-CoV-2: a storm is raging. J. Clin. Invest. 130, 2202-2205. doi: 10.1172/JCI137647

Pilotto, A., Benussi, A., Libri, I., Masciocchi, S., Poli, L., Premi, E., et al. (2021). COVID-19 impact on consecutive neurological patients admitted to the emergency department. J. Neurol. Neurosurg. Psychiatry 92, 218-220. doi: 10.1136/jnnp-2020-323929

Poloni, T. E., Carlos, A.F., Cairati, M., Cutaia, C., Medici, V., Marelli, E., et al. (2020). Prevalence and prognostic value of Delirium as the initial presentation of COVID-19 in the elderly with dementia: an Italian retrospective study. EClinicalMedicine 26:100490. doi: 10.1016/j.eclinm.2020.100490

Poyiadji, N., Shahin, G., Noujaim, D., Stone, M., Patel, S., and Griffith, B. (2020). COVID-19-associated acute hemorrhagic necrotizing encephalopathy: imaging features. Radiology 296, E119-E120. doi: 10.1148/radiol.202 0201187

Qin, C., Zhou, L., Hu, Z., Zhang, S., Yang, S., Tao, Y., et al. (2020). Dysregulation of immune response in patients with COVID-19 in Wuhan, China. Clin. Infect. Dis. 71, 762-768. doi: 10.1093/cid/ciaa248

Reichard, R. R., Kashani, K. B., Boire, N. A., Constantopoulos, E., Guo, Y., and Lucchinetti, C. F. (2020). Neuropathology of COVID-19: a spectrum of vascular and acute disseminated encephalomyelitis (ADEM)-like pathology. Acta Neuropathol. 140, 1-6. doi: 10.1007/s00401-02002166-2

Rogers, A. A., Ha, T., and Ockey, S. (2021). Adolescents' perceived socio-emotional impact of COVID-19 and implications for mental health: results from a U.S. based mixed-methods study. J. Adolesc. Health 68, 43-52. doi: 10.1016/j. jadohealth.2020.09.039

Romero-Sanchez, C. M., Diaz-Maroto, I., Fernandez-Diaz, E., SanchezLarsen, A., Layos-Romero, A., Garcia-Garcia, J., et al. (2020). Neurologic manifestations in hospitalized patients with COVID-19: the ALBACOVID 
registry. Neurology 95, e1060-e1070. doi: 10.1212/WNL.0000000000 009937

Sardu, C., Gambardella, J., Morelli, M. B., Wang, X., Marfella, R., and Santulli, G. (2020). Hypertension, thrombosis, kidney failure and diabetes: is COVID-19 an endothelial disease? A comprehensive evaluation of clinical and basic evidence. J. Clin. Med. 9:1417. doi: 10.3390/jcm9051417

Serrano-Castro, P. J., Estivill-Torrus, G., Cabezudo-Garcia, P., Reyes-Bueno, J. A., Ciano Petersen, N., Aguilar-Castillo, M. J., et al. (2020). Impact of SARS-CoV-2 infection on neurodegenerative and neuropsychiatric diseases: a delayed pandemic? Neurologia 35, 245-251. doi: 10.1016/j.nrl.2020. 04.002

Signaling, N. B., Frieman, M., Ratia, K., Johnston, R. E., Mesecar, A. D., and Baric, R. S. (2009). Severe acute respiratory syndrome coronavirus papain-like protease ubiquitin-like domain and catalytic domain regulate antagonism of. J. Virol. 83, 6689-6705. doi: 10.1128/JVI.02220-08

Sohal, S., and Mansur, M. (2020). COVID-19 presenting with seizures. IDCases 20:e00782.doi: 10.1016/j.idcr.2020.e00782doi: 10.1016/j.idcr.2020. e00782

Solomon, I. H., Normandin, E., Bhattacharyya, S., Mukerji, S. S., Keller, K., Ali, A. S., et al. (2020). Neuropathological features of Covid-19. N. Engl. J. Med. 383, 989-992. doi: 10.1056/NEJMc2019373

Soltan, A. A., Kouchaki, S., Zhu, T., Kiyasseh, D., Taylor, T., Hussain, Z. B., et al. (2020). Rapid triage for COVID-19 using routine clinical data for patients attending hospital: development and prospective validation of an artificial intelligence screening test. Lancet Digit. Health 3, e78-e87. doi: 10.1016/S25897500(20)30274-0

Sotoca, J., and Rodriguez-Alvarez, Y. (2020). COVID-19-associated acute necrotizing myelitis. Neurol. Neuroimmunol. Neuroinflamm. 7:e803. doi: 10.1212/NXI.0000000000000803

Suwanwongse, K., and Shabarek, N. (2020). Rhabdomyolysis as a presentation of 2019 novel Coronavirus disease. Cureus 12:e7561. doi: 10.7759/cureus.7561

Toscano, G., Palmerini, F., Ravaglia, S., Ruiz, L., Invernizzi, P., Cuzzoni, M. G., et al. (2020). Guillain-barre syndrome associated with SARS-CoV-2. N. Engl. J. Med. 382, 2574-2576. doi: 10.1056/NEJMc2009191

Troyer, E. A., Kohn, J. N., and Hong, S. (2020). Are we facing a crashing wave of neuropsychiatric sequelae of COVID-19? Neuropsychiatric symptoms and potential immunologic mechanisms. Brain Behav. Immun. 87, 34-39. doi: 10.1016/j.bbi.2020.04.027

Tsai, S. T., Lu, M. K., San, S., and Tsai, C. H. (2020). The neurologic manifestations of Coronavirus disease 2019 pandemic: a systemic review. Front. Neurol. 11:498. doi: 10.3389/fneur.2020.00498

Varatharaj, A., Thomas, N., Ellul, M. A., Davies, N. W. S., Pollak, T. A., Tenorio, E. L., et al. (2020). Neurological and neuropsychiatric complications of COVID-19 in 153 patients: a UK-wide surveillance study. Lancet Psychiatry 7, 875-882. doi: 10.1016/S2215-0366(20)30287-X

Venkatesan, A., Tunkel, A. R., Bloch, K. C., Lauring, A. S., Sejvar, J., Bitnun, A., et al. (2013). Case definitions, diagnostic algorithms and priorities in encephalitis: consensus statement of the international encephalitis consortium. Clin. Infect. Dis. 57, 1114-1128. doi: 10.1093/cid/cit458

Wan, Y., Shang, J., Graham, R., Baric, R. S., and Li, F. (2020). Receptor recognition by the novel coronavirus from wuhan: an analysis based on decade-long structural studies of SARS Coronavirus. J. Virol. 94, e00127-e00120. doi: 10.1128/JVI.00127-20

Wang, B., Li, R., Lu, Z., and Huang, Y. (2020a). Does comorbidity increase the risk of patients with COVID-19: evidence from meta-analysis. Aging 12, 6049-6057. doi: 10.18632/aging.103000

Wang, D., Hu, B., Hu, C., Zhu, F., Liu, X., Zhang, J., et al. (2020b). Clinical characteristics of 138 hospitalized patients with 2019 novel Coronavirus-infected pneumonia in Wuhan, China. JAMA 323, 1061-1069. doi: 10.1001/jama.2020.1585

Wei, J., Xu, H., Xiong, J., Shen, Q., Fan, B., Ye, C., et al. (2020). 2019 novel Coronavirus (COVID-19) pneumonia: serial computed tomography findings. Korean J. Radiol. 21, 501-504. doi: 10.3348/kjr.2020.0112
Wittbold, K. A., Carroll, C., Iansiti, M., Zhang, H. M., and Landman, A. B. (2020). How hospitals are using AI to battle Covid-19. Harvard Business Review. Available online at: https://hbr.org/2020/04/how-hospitals-are-usingai-to-battle-covid-19. Accessed April 03, 2020.

Wong, R. S. M., Wu, A., To, K. F., Lee, N., Lam, C. W. K., Wong, C. K., et al. (2003). Haematological manifestations in patients with severe acute respiratory syndrome: retrospective analysis. BMJ 326, 1358-1362. doi: 10.1136/bmj.326. 7403.1358

Wu, Y., Xu, X., Chen, Z., Duan, J., Hashimoto, K., Yang, L., et al. (2020). Nervous system involvement after infection with COVID-19 and other coronaviruses. Brain Behav. Immun. 87, 18-22. doi: 10.1016/j.bbi.2020.03.031

Xu, X., Chen, P., Wang, J., Feng, J., Zhou, H., Li, X., et al. (2020). Evolution of the novel coronavirus from the ongoing Wuhan outbreak and modeling of its spike protein for risk of human transmission. Sci. China Life Sci. 63, 457-460. doi: 10.1007/s11427-020-1637-5

Yaghi, S., Ishida, K., Torres, J., Mac Grory, B., Raz, E., Humbert, K., et al. (2020). SARS-CoV-2 and stroke in a new york healthcare system. Stroke 51, 2002-2011. doi: 10.1161/STROKEAHA.120.030335

Yavarpour-Bali, H., and Ghasemi-Kasman, M. (2020). Update on neurological manifestations of COVID-19. Life Sci. 257:118063. doi: 10.1016/j.lfs.2020. 118063

Ylikoski, J., Markkanen, M., and Makitie, A. (2020). Pathophysiology of the COVID-19 - entry to the CNS through the nose. Acta Otolaryngol. 140, 886-889. doi: 10.1080/00016489.2020.1773533

Zaki, A. M., van Boheemen, S., Bestebroer, T. M., Osterhaus, A. D. M. E., and Fouchier, R. A. M. (2012). Isolation of a novel coronavirus from a man with pneumonia in Saudi Arabia. N. Engl. J. Med. 367, 1814-1820. doi: 10.1056/NEJMoa1211721

Zanin, L., Saraceno, G., Panciani, P. P., Renisi, G., Signorini, L., Migliorati, K., et al. (2020). SARS-CoV-2 can induce brain and spine demyelinating lesions. Acta Neurochir. 162, 1491-1494. doi: 10.1007/s00701-02004374-x

Zhang, X., Chen, X., Chen, L., Deng, C., Zou, X., Liu, W., et al. (2020). The evidence of SARS-CoV-2 infection on ocular surface. Ocul. Surf. 18, 360-362. doi: $10.1016 /$ j.jtos.2020.03.010

Zhao, K., Huang, J., Dai, D., Feng, Y., Liu, L., and Nie, S. (2020a). Acute myelitis after SARS-CoV-2 infection: a case report. medRxiv [Preprint] doi: 10.1101/2020.03.16.20035105

Zhao, H., Shen, D., Zhou, H., Liu, J., and Chen, S. (2020b). Guillain-Barre syndrome associated with SARS-CoV-2 infection: causality or coincidence? Lancet Neurol. 19, 383-384. doi: 10.1016/S1474-4422(20)30109-5

Zheng, H., Zhang, M., Yang, C. X., Zhang, N., Wang, X. C., Yang, X. P., et al. (2020). Elevated exhaustion levels and reduced functional diversity of $T$ cells in peripheral blood may predict severe progression in COVID-19 patients. Cell. Mol. Immunol. 17, 541-543. doi: 10.1038/s41423-020-0401-3

Zhou, H., Lu, S., Chen, J., Wei, N., Wang, D., Lyu, H., et al. (2020a). The landscape of cognitive function in recovered COVID-19 patients. J. Psychiatr. Res. 129, 98-102. doi: 10.1016/j.jpsychires.2020.06.022

Zhou, L., Zhang, M., Wang, J., and Gao, J. (2020b). Sars-Cov-2: underestimated damage to nervous system. Travel Med. Infect. Dis. 36:101642. doi: 10.1016/j. tmaid.2020.101642

Conflict of Interest: The authors declare that the research was conducted in the absence of any commercial or financial relationships that could be construed as a potential conflict of interest.

Copyright (c) 2021 Kalra, Dhanjal, Meena, Kalel, Dahiya, Singh, Dewanjee and Kandimalla. This is an open-access article distributed under the terms of the Creative Commons Attribution License (CC BY). The use, distribution or reproduction in other forums is permitted, provided the original author(s) and the copyright owner(s) are credited and that the original publication in this journal is cited, in accordance with accepted academic practice. No use, distribution or reproduction is permitted which does not comply with these terms. 